\title{
REVISED Recent Developments in Tuberculous Meningitis
}

\section{Pathogenesis and Diagnostics [version 3; peer review: 3}

\section{approved]}

\author{
Fiona V Cresswell (iD1-3, Angharad G. Davis (iD) 4-6, Kusum Sharma7, \\ Robindra Basu Roy1, Ahmad Rizal Ganiem', Enock Kagimu (iD), \\ Regan Solomons (id), Robert J. Wilkinson (id5,6,10, Nathan C Bahr(D11, \\ Nguyen Thuy Thuong Thuong12, \\ Tuberculous Meningitis International Research Consortium
}

\footnotetext{
${ }^{1}$ Clinical Research Department, London School of Hygiene and Tropical Medicine, London, WC1E 7HT, UK

${ }^{2}$ Research Department, Infectious Diseases Institute, Kampala, PO Box 22418, Uganda

${ }^{3}$ MRC-UVRI-London School of Hygiene and Tropical Medicine Uganda Research Unit, Entebbe, Uganda

4 University College London, London, WC1E6BT, UK

${ }^{5}$ Francis Crick Institute, London, NW1 1AT, UK

${ }^{6}$ Department of Medicine, Institute of Infectious Diseases and Molecular Medicine, University of Cape Town, 7925, South Africa

${ }^{7}$ Department of Medical Microbiology, Post-graduate Department of Medical Education and Research, Chandigahr, India

${ }^{8}$ Department of Neurology, Hasan Sadikin Hospital, Faculty of Medicine. Universitas Padjadjaran, Bandung, Indonesia

${ }^{9}$ Department of Paediatrics and Child Health, Faculty of Medicine and Health Sciences, Stellenbosch University, South Africa

${ }^{10}$ Department of Infectious Diseases, Imperial College, London, W2 1PG, UK

${ }^{11}$ Division of Infectious Diseases. Department of Medicine., University of Kansas, Kansas City, USA

${ }^{12}$ Oxford University Clinical Research Unit, Ho Chi Minh City, Vietnam
}

V3 First published: 31 Oct 2019, 4:164

https://doi.org/10.12688/wellcomeopenres.15506.1

Second version: 06 Jul 2020, 4:164

https://doi.org/10.12688/wellcomeopenres.15506.2

Latest published: 28 Jan 2021, 4:164

https://doi.org/10.12688/wellcomeopenres.15506.3

\section{Abstract}

The pathogenesis of Tuberculous meningitis (TBM) is poorly understood, but contemporary molecular biology technologies have allowed for recent improvements in our understanding of TBM. For instance, neutrophils appear to play a significant role in the immunopathogenesis of TBM, and either a paucity or an excess of inflammation can be detrimental in TBM. Further, severity of HIVassociated immunosuppression is an important determinant of inflammatory response; patients with the advanced immunosuppression (CD4+ T-cell count of $<150$ cells $/ \mu \mathrm{L}$ ) having higher CSF neutrophils, greater CSF cytokine concentrations and higher mortality than those with CD4+ T-cell counts $>150$ cells/ $\mu \mathrm{L}$. Host genetics may also influence outcomes with LT4AH genotype predicting inflammatory phenotype, steroid responsiveness and survival in Vietnamese adults with TBM. Whist in Indonesia, CSF

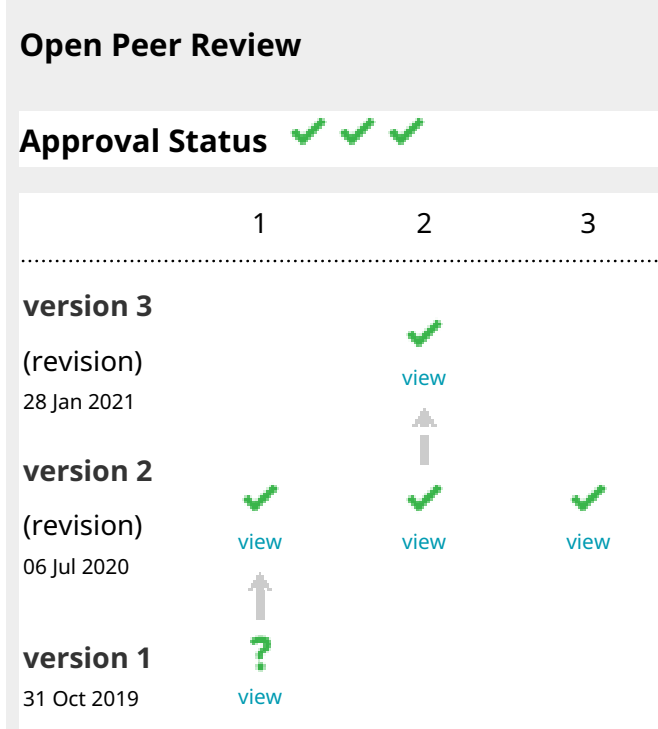

1. James E. Scriven ID, University of Birmingham, Birmingham, UK 
tryptophan level was a predictor of survival, suggesting tryptophan metabolism may be important in TBM pathogenesis. These varying responses mean that we must consider whether a "one-size-fits-all" approach to anti-bacillary or immunomodulatory treatment in TBM is truly the best way forward. Of course, to allow for proper treatment, early and rapid diagnosis of TBM must occur. Diagnosis has always been a challenge but the field of TB diagnosis is evolving, with sensitivities of at least $70 \%$ now possible in less than two hours with GeneXpert MTB/Rif Ultra. In addition, advanced molecular techniques such as CRISPR-MTB and metagenomic next generation sequencing may hold promise for TBM diagnosis. Host-based biomarkers and signatures are being further evaluated in childhood and adult TBM as adjunctive biomarkers as even with improved molecular assays, cases are still missed. A better grasp of host and pathogen behaviour may lead to improved diagnostics, targeted immunotherapy, and possibly biomarker-based, patient-specific treatment regimens.

Keywords

Tuberculous meningitis, TBM, TB, HIV, pathogenesis, diagnostics,

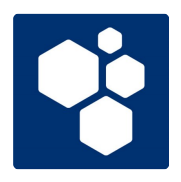

This article is included in the Wellcome Centre

for Infectious Diseases Research in Africa

(CIDRI-Africa) gateway.

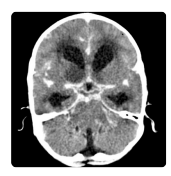

This article is included in the Tuberculous

Meningitis International Research Consortium

collection.
2. Joseph Zunt, University of Washington,

Seattle, USA

3. Michael J. Griffiths (iD), University of

Liverpool, Liverpool, UK

Any reports and responses or comments on the article can be found at the end of the article. 


\section{Corresponding author: Fiona V Cresswell (fiona.cresswell@ishtm.ac.uk)}

Author roles: Cresswell FV: Conceptualization, Methodology, Project Administration, Writing - Original Draft Preparation, Writing Review \& Editing; Davis AG: Conceptualization, Methodology, Writing - Original Draft Preparation, Writing - Review \& Editing; Sharma K: Writing - Original Draft Preparation; Basu Roy R: Writing - Original Draft Preparation, Writing - Review \& Editing; Ganiem AR: Writing Original Draft Preparation; Kagimu E: Writing - Original Draft Preparation; Solomons R: Methodology, Writing - Original Draft Preparation, Writing - Review \& Editing; Wilkinson RJ: Methodology, Writing - Original Draft Preparation, Writing - Review \& Editing; Bahr NC: Conceptualization, Methodology, Writing - Original Draft Preparation, Writing - Review \& Editing; Thuong NTT: Conceptualization, Methodology, Writing - Original Draft Preparation, Writing - Review \& Editing;

Competing interests: No competing interests were disclosed.

Grant information: This work is supported by the Wellcome Trust through a Wellcome Clinical PhD Fellowship to FVC [210772], a UCL Wellcome Trust PhD Programme for Clinicians Fellowship award to AGD [175479], a Wellcome Trust intermediate Fellowship to NTTT [206724], support to the Francis Crick Institute [FC0010218] and grants to RJW [104803, 203135]. NCB is supported by the National Institute of Neurological Disorders and Stroke (K23 NS110470) within the National Institutes of Health. RJW is also supported by the Francis Crick Institute which receives support from Wellcome [FC0010218], CRUK [FC0010208]; Meningitis Now; and the European and Developing Countries Clinical Trials Partnership (EDCTP). RS is supported by the National Research Foundation of South Africa [109437]. This work was supported by the Wellcome Trust through funding to the Tuberculous Meningitis International Research Consortium. The funders had no role in study design, data collection and analysis, decision to publish, or preparation of the manuscript.

Copyright: @ 2021 Cresswell FV et al. This is an open access article distributed under the terms of the Creative Commons Attribution License, which permits unrestricted use, distribution, and reproduction in any medium, provided the original work is properly cited.

How to cite this article: Cresswell FV, Davis AG, Sharma K et al. Recent Developments in Tuberculous Meningitis Pathogenesis and Diagnostics [version 3; peer review: 3 approved] Wellcome Open Research 2021, 4:164 https://doi.org/10.12688/wellcomeopenres.15506.3

First published: 31 Oct 2019, 4:164 https://doi.org/10.12688/wellcomeopenres.15506.1 


\section{REVISED Amendments from Version 2}

In light of comments from the reviewers, we have added a little more detail in relation to the CSF biomarkers in children, RNA signatures and added a table summarising CSF assays for TBM.

Any further responses from the reviewers can be found at the end of the article

\section{Introduction}

The pathogenesis of Tuberculous meningitis (TBM) is poorly understood. Mechanisms by which Mycobacteria disseminate from lung to the brain, key factors driving a dysregulated host response, and the pathogen specific factors influencing presentation and severity, compared to other forms of TB, are not well described. In recent years application of contemporary molecular biology 'omics' techniques to clinical samples, greater availability of advanced neuroradiology, emphasis on immune-mediated contributions to pathology, and use of refined experimental models of TBM have better illuminated its pathogenesis. A better grasp of these processes may also lead to improved diagnostics, targeted immunotherapy as well as a biomarker-based, patient-specific approach to personalized treatment. Diagnosis has been traditionally insensitive (AFB smear) and slow (culture). This has improved with the addition of GeneXpert MTB/Rif (Xpert) which gave sensitivities similar to culture in 2 hours (versus 2-4 weeks with culture). Subsequently, GeneXpert MTB/Rif Ultra (Ultra), a re-engineered version, has shown better sensitivities than culture in some settings. Yet, none of these technologies has adequate negative predictive value to 'rule-out' TBM. In this article we review important recently published studies that have informed our current understanding of TBM pathogenesis and diagnostics. We do not seek to present a comprehensive review of the history of TBM pathogenesis and diagnostics as a number of detailed papers have addressed this recently ${ }^{1-3}$. Rather we provide a commentary of key studies published within the last 5 years and summarise knowledge gaps and future considerations to enable progress in the field.

\section{TBM pathogenesis}

\section{Dissemination to the central nervous system}

Understanding of the microbial and immune processes that allow $M$. tuberculosis to disseminate from the respiratory epithelium to reach the meninges remains incomplete ${ }^{2,4}$. The foundations of what is known were laid through natural history and autopsy studies in the pre-chemotherapy era. The necessary steps to develop TBM include the pathogen surviving its initial encounter with the innate immune system at the respiratory epithelium and establishment of primary infection in the lung parenchyma with characteristic granulomatous inflammation ${ }^{5-7}$. Spread beyond the lungs likely occurs through the blood and may be preceded by local invasion to the lymphatic system. Donald and Schoeman have highlighted the possibility of coincident miliary TB in cases of TBM, particularly in young children, where tubercles of different sizes and ages have been described on the meninges and confirmed by magnetic resonance imaging $(\mathrm{MRI})^{8,9}$. In children, miliary TB and TBM develop most often within 3 months of primary infection, when fresh anatomical changes are still found in the primary lung focus ${ }^{10}$. In addition to children, people living with HIV (PLWHIV) are another vulnerable group who may be unable to control the infection in the lungs and therefore at risk of coincident miliary TB and TBM secondary to haematogenous dissemination of $M . t b^{8,11}$. The contemporaneous nature of TBM and miliary TB illustrates that the "Rich focus" model (of a single meningeal/sub-cortical granuloma rupturing years after initial haematogenous dissemination discharging acid-fast bacilli into the sub-arachnoid space $)^{12}$ does not apply to all TBM cases and there may be more than one pathway to the development of meningitis following M. tuberculosis infection.

\section{Host immune response to TB infection in the CNS}

The host immune response to TB bacilli in the sub-arachnoid space gives rise to a granulomatous inflammation predominantly affecting the basal meninges. Inflammatory exudates may obstruct the passage of cerebrospinal fluid (CSF), leading to hydrocephalus. Small and medium-sized intracerebral arteries can become inflamed and occluded, leading to cerebral infarcts. The majority of TBM pathology is believed to result from the host inflammatory response, which has been reviewed in depth elsewhere ${ }^{2}$; several pro- and anti-inflammatory cytokines such as tumour necrosis factor- $\alpha$ (TNF- $\alpha$ ), interferon- $\gamma$ (IFN- $\gamma$ ), interleukin (IL) $1 \beta$, IL-6, IL- 8 , and IL-10 are shown to be induced in $\mathrm{TBM}^{13,14}$. Disequilibrium of pro- and anti-inflammatory cytokines influence the severity and course of TBM. Current understanding of key established mechanisms known to play a role in host immune response in TBM are summarised in Figure $1^{2,15}$.

In the recent literature, the long-standing belief that excessive inflammation is the cause of death in TBM was brought into question by a recent immunopathogenesis study in Vietnam. In HIV-negative adults, associations between death and both lower CSF cytokines concentrations and lower CSF leucocyte counts (median $59 \times 10^{3}$ cells $/ \mathrm{mL}\left(\mathrm{IQR} 13-240 \times 10^{3}\right.$ cells $/ \mathrm{mL}$ ) in those who died versus $135 \times 10^{3}$ cells $/ \mathrm{mL}$ (IQR, 48-298 $\times 10^{3}$ cells $/ \mathrm{mL}$ ) in survivors) were noted ${ }^{16}$. These data support the notion that poor outcome from TBM, in the context of immunosuppressive treatment (adjunctive corticosteroids), is associated with an inadequate pretreatment inflammatory response in HIV-negative individuals. In a study of 120 Vietnamese adults with TBM included in a trial of adjunctive aspirin treatment, it was shown that there was an aspirin dose-dependent inhibition of thromboxane $\mathrm{A}_{2}$ and upregulation of pro-resolving CSF protectins, resulting in potential reduction in new infarcts and deaths by day 60 of treatment in microbiologically confirmed TBM patients ${ }^{17}$. A further study investigated concentrations of host protective lipid mediators (specialized proresolving mediators, SPMs) in CSF. Prostaglandins and cysteinyl leukotrienes were found to be reduced in more severe cases, while the lipoxygenase 5-derived 13-series resolvin (RvT)2, RvT4, and 15-epi-lipoxin B4, were significantly increased in survivors. These data suggest SPMs may play an important role in TBM pathogenesis ${ }^{18}$.

Among 608 Indonesian adults with suspected TBM, higher CSF and blood neutrophil counts (HR 1.10 (95\%CI 1.04-1.16) per $10 \%$ increase and HR 1.06 per $10^{9}$ neutrophils/L increase; 


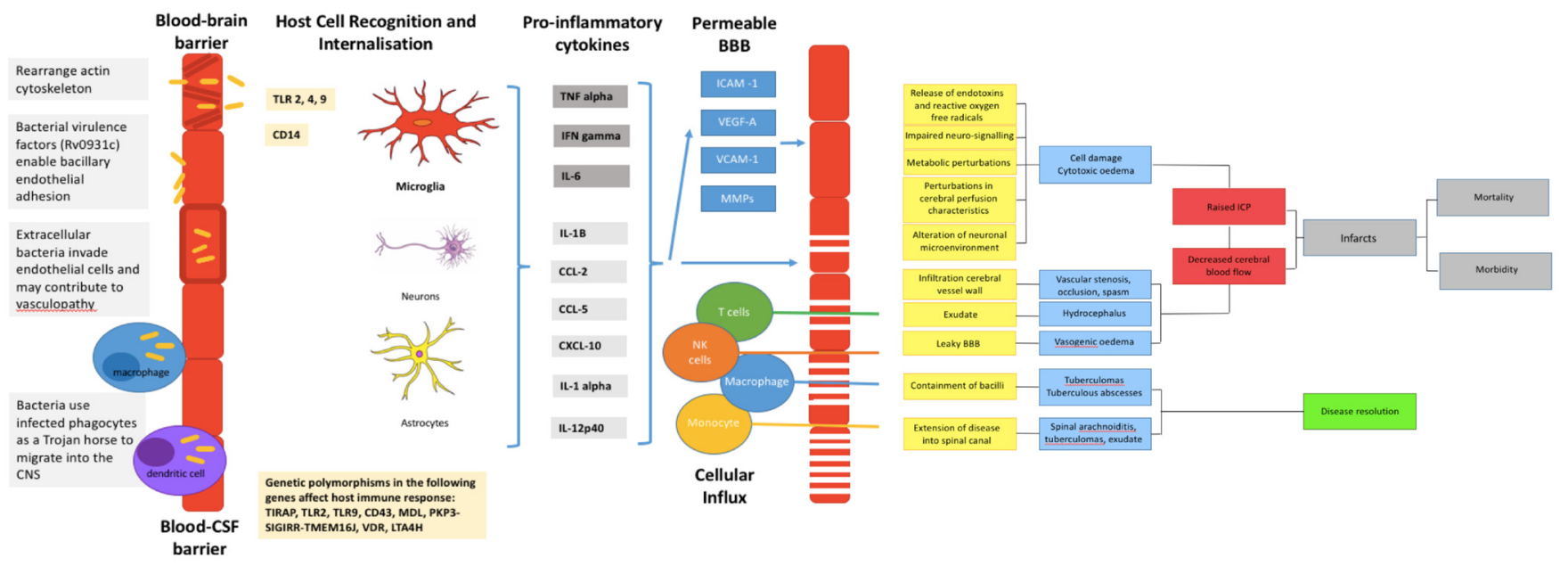

Figure 1. Illustrative summary of the pathogenesis of tuberculous meningitis (TBM). Reproduced with permission from author and Journal of Leukocyte Biology². A: Mycobacterium tuberculosis bacilli (M.tb) disseminate from the primary site of infection in the lung to seed the brain. The bacilli traverse the blood brain barrier (BBB) and blood cerebrospinal fluid barrier (BCSFB) through various virulence factors that enable the invasion of and migration through cerebral vascular endothelial cells, or are carried into the CNS by infected peripheral innate immune cells. B: In the CNS antigen recognition and internalization by microglia, neurons and astrocytes occurs, mediated by numerous host genetic factors. C: The resulting immune response stimulates the release of proinflammatory cytokines and chemokines and other immune mediators that contribute to the breakdown of the BBB and the influx of innate and adaptive immune cells from the periphery. D: A prolific inflammatory response ensues. The inflammatory exudate in the basal cisterns contributes to cerebral vascular pathology and the development of hydrocephalus and raised intracranial pressure. Vasogenic edema due to an influx of proteins through the leaky BBB, and cytotoxic edema as a result of cellular damage contribute to the raised pressure. The overall decrease in cerebral blood flow puts the brain at risk of ischemia, infarction and poor patient outcomes. In some cases the infection is controlled in discrete tuberculomas or abscesses, which may resolve with treatment and time.

(95\% CI 1.03-1.10), respectively) were associated with mortality ${ }^{19}$. Flow-cytometry on blood in a subset of 160 HIV-negative adults with TBM showed lower $\alpha \beta \mathrm{T}$ and $\gamma \delta \mathrm{T}$ cells, NK cells and MAIT cells in TBM subjects compared to 26 pulmonary TB adults (2.4 to 4-fold, all $\mathrm{p}<0.05)$ and 27 healthy controls (2.7-7.6-fold, $\mathrm{p}<0.001)$, but higher neutrophils and classical monocytes (2.3 - 3.0-fold, $\mathrm{p}<0.001)$. CSF flow cytometry of TBM patients showed a predominance of $\alpha \beta T$ and NK cells, associated with better survival, as well as the presence of MAIT cells, previously undescribed in $\mathrm{CSF}^{20}$. Indonesian HIV-negative TBM patients showed a strong myeloid blood response and a remarkably broad lymphoid CSF response including innate lymphocytes, however there was little correlation between blood and CSF compartments ${ }^{20}$.

These recent studies in Vietnamese and Indonesian adults with TBM, aimed at gaining insights into mechanisms of the inflammatory response in disease pathogenesis, used novel and high-resolution methods to look at lipid mediator profiles and immune cell populations. Data indicated specific lipid mediator signatures and cell populations that are associated with disease severity before treatment and mortality; these should beconsidered for host-directed therapy of TBM.

\section{Host genetic and metabolic factors}

More efficient and cost-effective genomics platforms have enabled of late better understanding of variable host responses in TBM through the study of host genetics. Polymorphisms in CD43 encoding a surface glycoprotein involved in M.tb adhesion and proinflammatory cytokine induction and PKP3-SIGIRRTMEM16J gene region encoding a negative regulator of TLR/IL-1R signalling have both been linked to survival in $\mathrm{TBM}^{21,22}$. However, the greatest interest has been around the role of leukotriene A4 hydrolase (LTA4H). LTA4H catalyzes the final step in the synthesis of leukotriene B4 (LTB4), a potent chemoattractant and pro-inflammatory eicosanoid. A common functional promoter variant rs17525495 in the LTA4H gene can predict survival and dexamethasone responsiveness in HIV-uninfected adults with $\mathrm{TBM}^{16,23}$. This human candidate gene association study was guided by findings in a zebra fish model where LTA4H was found to determine the balance of pro-inflammatory and anti-inflammatory eicosanoids in response to mycobacterial infection ${ }^{16,24}$. In a retrospective study in Vietnamese HIV-uninfected adults with TBM, while LTA4H rs17525495 TT and CC genotypes were both associated with susceptibility to mycobacterial infection, the associations involved opposing inflammatory states: high inflammation for the TT genotype and low inflammation for the CC genotype. CT genotype had an intermediate inflammatory response and were more likely to survive TBM. Dexamethasone treatment improved survival in TT genotype patients with hyperinflammatory response but was possibly harmful to $\mathrm{CC}$ patients with hypo-inflammatory response ${ }^{23}$. A later prospective study in Vietnam reported that in TBM HIV-uninfected adults, LTA4H genotype influences cytokine inflammatory response and correlates with TBM severity, Figure $2^{16}$. More importantly, this study confirmed that the LTA4H genotype determined corticosteroid responsiveness and survival. 

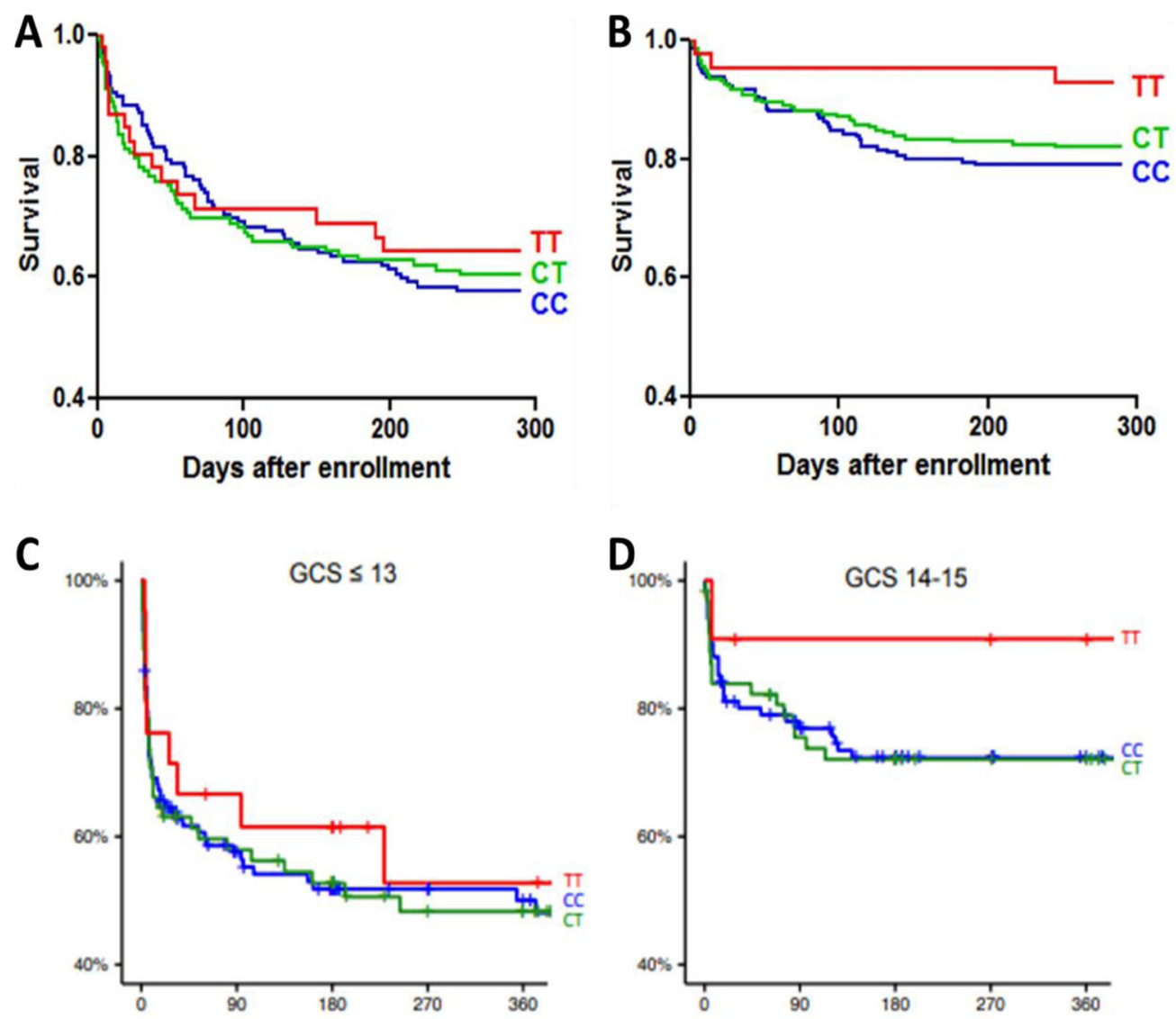

Figure 2. Kaplan-Meier survival curves stratified by LTA4H genotype. Figures $\mathbf{A}$ and $\mathbf{B}$ show survival in 763 patients with tuberculous meningitis in Vietnam ${ }^{16}$, with human immunodeficiency virus (HIV) infection (A), and without HIV infection (B). In HIV-infected patients, case-fatality rates were 34.8\% (16 of 46) in those with TT genotype, 42.1\% (61 of 145) in CT genotype, and 38.8\% (52 of 134) in CC genotype. In HIV-uninfected patients, case-fatality rates were $7.1 \%$ (3 of 42) in TT, 21.4\% (40 of 187) in CT, and 18.7\% (39 of 209) in CC. Figures C and D show survival in 375 patients with tuberculous meningitis in Indonesia ${ }^{19}$. These patients are HIV-uninfected with severe (GCS $\left.\leq 13\right)(\mathbf{C})$ or milder (GCS 14-15) disease (D). In a recessive model, TT genotype versus CT/TT combined had HR 0.81 (95\% CI 0.41-1.62, p =.550) in severe and 0.31 (95\% CI 0.04-2.25, $p=.156)$ in milder disease.

Interestingly, LTA4H genotype did not predict outcomes in Indonesian adults with TBM, but there was a trend towards improved survival with TT genotype compared to CC or CT genotype, Figure $2^{19}$. A clinical trial is currently underway in Vietnam (NCT03100786) to evaluate LTA4H genotype-directed corticosteroid therapy, an exciting example of personalised medicine in $\mathrm{TBM}^{25}$.

Although prior studies have considered sodium, glucose and lactate as related to TBM pathogenesis, recent developments in the application of targeted metabolomics have provided greater insight in the role of tryptophan, a potential key metabolite in TBM. This amino acid required for protein biosynthesis is a precursor to serotonin and melatonin (serotonin pathway) and kynurenine and quinolinic acid (kynurenine pathway). The latter is stimulated at the expense of the former by pro-inflammatory cytokine such as IL-6, TNF-alpha and IFN-gamma via indoleamine 2, 3-dioxygenase. In a recent study of serum and CSF metabolites, low levels of tryptophan were associated with survival ${ }^{26}$. One theory regarding this association could be the neuroprotective effects of the associated kynurenine pathway downstream metabolites. Either this pathway, or the 11 genetic foci related to CSF tryptophan metabolism could have novel clinical implications for $\mathrm{TBM}^{26}$.

\section{HIV co-infection and immune reconstitution inflammatory syndrome}

HIV infection is a strong independent predictor of death from TBM (hazard ratio, 3.94; 95\% confidence interval (CI), 2.79-5.56 $)^{27}$. The role of adjunctive corticosteroids in HIV-associated TBM is inconclusive (relative risk of death with adjunctive steroids, $0.78 ; 95 \% \mathrm{CI}, 0.59$ to $1.04 ; \mathrm{P}=0.08)^{28}$ and a randomized placebo-controlled trial is underway (NCT03092817) to address the use of steroids in HIV-associated TBM. Pathogenesis studies in PLWHIV are required to identify the unique pathogenic determinants of poor prognosis. Thuong et al. compared the pretreatment CSF cells and cytokine profiles of 764 HIV-positive and HIV-negative participants in Vietnamese TBM clinical trials. HIV-positive individuals had higher mean CSF neutrophil percentage $(17 \%$ vs $5 \%$; $\mathrm{P}<.0001)$ 
and global cytokine expression (aside from IL-10 which inhibits response to $M$. tuberculosis) than their HIV-negative counterparts. PLWHIV with CD4+ T-cell counts $<150$ cells $/ \mu \mathrm{L}$ showed higher median CSF neutrophil percentage (25\%), than those with a count $\geq 150$ cells/ $\mu \mathrm{L}$ (neutrophils $10 \% ; \mathrm{P}=0.021$ ) and patients without HIV infection (neutrophils 5\%; $\mathrm{P}<0.0001$ ). Of patients with a CD4+ T-cell count of $<150$ cells $/ \mu \mathrm{L}, 44 \%$ (105 of 238) died, compared with $13 \%$ (5 of 39) with a count of $\geq 150$ cells $/ \mu \mathrm{L}$ and $19 \%$ (83 of 439 ) without HIV infection ${ }^{16}$. These findings, amongst others, suggest a role for neutrophils in the immunopathogenesis of HIV-associated $\mathrm{TBM}^{29}$.

Marais et al. conducted longitudinal analyses of paired blood and CSF samples in South Africans with HIV-associated TBM, describing the relationships between the development of immune reconstitution inflammatory syndrome (IRIS) and CSF leucocytes, the concentrations of $>30$ blood and CSF inflammatory mediators, and blood transcriptional profiles. They found TBM-associated CNS IRIS to have an inflammatory signature characterized by neutrophil and inflammasome-mediated proinflammatory responses ${ }^{30,31}$. The neutrophil-dependent inflammatory activation could be detected in peripheral blood before the start of TB treatment and therefore has potential to predict who will develop IRIS.

\section{Brain Injury Markers}

The study of neurodegenerative-associated proteins to describe extent and type of brain injury post TBM has recently been explored through omics analysis, approaches which strive to understand genetic or molecular profiles of humans, particularly in paediatric TBM. In lumbar CSF of children with TBM, S100B and NSE (structural proteins of the CNS, and biomarkers of CNS tissue damage) at disease onset were associated with poor outcome, as was highest concentration overall and an increasing profile over time in S100B, NSE, and GFAP neuromarker concentrations increased over time in those who died (whilst inflammatory markers decreased), and were overall highest in those with cerebral infarction ${ }^{32}$. It is of interest that despite markers of inflammation reducing, proteins traditionally associated with neurodegenerative processes continued to rise.

In ventricular CSF of children with TBM, transcriptome analysis has revealed significant enrichment of transcripts associated with neuro-excititoxicity predominantly driven by glutamate release and NMDA binding and receptor uptake ${ }^{33}$. Upregulation of genes associated with nitric oxide, cytochrome c, brain injury proteins like myelin basic protein, and proteins including tau, amyloidbeta and apo- lipoprotein were also seen ${ }^{33}$; many of which have also been described in in neurodegenerative conditions such as Alzhiemer's disease and traumatic brain injury ${ }^{34}$.

These findings raise the possibility of ongoing brain injury which in TBM seem to occur following ischaemic injury, despite resolving acute inflammation ${ }^{32}$. Further studies, including those which investigate the longer-term pathogenic processes in TBM are required to validate these results and understand further neurological sequelae including those which may indicate a post-infectious process in TBM.

\section{Neuroimaging in pathogenesis studies}

Technical advances and increasing availability of imaging modalities have recently enabled research in which imaging is used to assess pathogenic mechanisms in TBM in vivo in animal and human subjects. In a blood and CSF biomarker study of childhood TBM tuberculomas, magnetic resonance imaging has been used to note an association between tuberculomas and elevated interleukin (IL) $12 \mathrm{p} 40$, interferon-inducible protein 10 , and monocyte chemoattractant protein 1 concentrations, whereas infarcts were associated with elevated TNF- $\alpha$, macrophage inflammatory protein $1 \alpha$, IL- 6 , and IL- $8^{32}$. Specific sequences can also be used to describe morphology of structural damage and correlate this to meaningful clinical measures. For instance poorer Diffusion Tensor Imaging (DTI) parameters of white matter integrity in the anterior cingulate gyrus, parahippocampal gyrus and globus pallidus are associated with worse neuropsychological performance ${ }^{35}$. A further study by the same group used Diffeomorphic Anatomical Registration Through Exponentiated Lie Algebra (DARTEL) voxel-based morphometry (VBM) to assess the integrity of grey matter in these same TBM patients $^{36}$. Patients with TBM performed significantly poorer on the digit symbol, similarities, block design, matrix reasoning, and letter-number sequencing subtests of the Wechsler Adult Intelligence Scale compared to healthy adults. These changes correlated with smaller grey matter volumes in the right thalamus, right superior temporal gyrus, right precuneus, right middle temporal gyrus, left putamen, right caudate nucleus, and right middle temporal gyrus ${ }^{36}$. These studies suggest that structural damage can be cortical as well as subcortical which may in turn be related to degree of long-term impairment. This has implications for understanding long term outcomes particularly neurocognitive impairment in TBM, which in light of these findings may share features with other forms of dementia (including vascular and HIV associated neurocognitive impairment) where a subcortical pattern of neurocognitive impairment (including frontal and executive functions) can be observed.

A rabbit model study of childhood TBM, utilized ionized calcium binding adapter molecule (Iba-1) to approximate microglial activation with flurodeoxyglucose-positron emission tomography (FDG-PET) and demonstrated the presence of activated microglia and macrophages localized to TB lesions ${ }^{37}$. In humans, case reports and a prospective study have advocated the use of FDG-PET as a diagnostic tool, as it has been effective in detecting extra-cranial evidence supportive of a TBM diagnosis ${ }^{38-40}$. The role of FDG-PET in unravelling time course of inflammation in TBM remains to be seen, although it has played a role in understanding Alzheimer's, a disease in which, similar to TBM, inflammation plays a key pathogenic role ${ }^{41,42}$.

\section{Pathogen factors: bacillary load, pathogen strain and virulence factors}

TBM patients generally have low bacterial loads in CSF which causes difficulties in both diagnosis and ability to study bacterial load evolution-related pathophysiology. The time-to-positivity of a culture and cycle threshold $(\mathrm{Ct})$ of nucleic acid amplification tests such as GeneXpert MTB/Rif (Xpert) can provide an indication of likely bacterial burden ${ }^{43}$. Over $50 \%$ of diagnosed cases are microbiologically undetectable and defined as 
'probable' or 'possible' TBM which obviously limits this approach $^{44}$. Marais et al. showed that in patients where M.tb was cultured from CSF taken before and after two weeks of antituberculosis treatment, there was a 9.3-fold increased risk of subsequently developing TBM-IRIS, although the sample size is small with 15 TBM-IRIS patients compared with 6 non-TBM-IRIS patients ${ }^{45}$. Thuong et al. found that among 692 Vietnamese adults with TBM, pre-treatment CSF M.tb load (by Xpert $\mathrm{Ct}$ ) was correlated with increased CSF neutrophil counts, increased cytokine production, and new neurological events after treatment initiation, but not death ${ }^{43}$.

In addition, epidemiological trends of M.tb lineage from TBM $(\mathrm{n}=73)$ and pulmonary TB $(\mathrm{n}=220)$ patients in Thailand showed that the Indo-Oceanic lineage is more frequently found in TBM patients $(41 \% \text { versus } 13 \% \text { in PTB })^{46}$. This association did not hold true in Indonesia, though specific genetic variations were identified which were associated with TB phenotype, including one (Rv0218) whose encoded protein may play a role in host-pathogen interaction ${ }^{47}$.

\section{Host-pathogen interactions}

It is estimated that the global burden of latent TB infection (LTBI) is approximately $23.0 \%$ (95\% CI $20.4 \%-26.4 \%$ ), amounting to approximately 1.7 billion people ${ }^{48}$. Innate immune responses are critical to control TB infection yet also contribute to tissue damage. This delicate balance is illustrated in the damage response framework which provides a theory of microbial pathogenesis that incorporates the contributions of both host and microbe to host damage that stems from host-microbe interaction $^{49,50}$. This framework likely applies to TBM based on evidence of both failed immunity and excessive inflammation being linked to increased TBM pathology, see Figure $3^{23,51,52}$. Both the microbe and the host contribute to host damage and where an individual patient's immune response lies on the continuum of the damage response framework parabola determines the nature of the disease process ${ }^{16,43,53}$. Evidence from recent studies shows $L T A 4 H$ genotype, CSF cytokines and CSF immune cells such as neutrophils are determinants of inflammatory state, which impacts both bacterial growth and host damage and thus leads to different outcomes. The current one-size-fits-all approach to TBM treatment fails to recognize divergent pathologies and may explain the poor outcomes in certain populations. Being able to identify where on the parabola an individual lies and tailoring therapy to achieve the optimal milieu is an approach that warrants further investigation. LTA $4 H$ genotype is an example of using host genotype to predict inflammatory response and to tailor treatment by host directed therapy. Omics technology are now being used to identify additional host genetic markers and treatment targets in TBM.

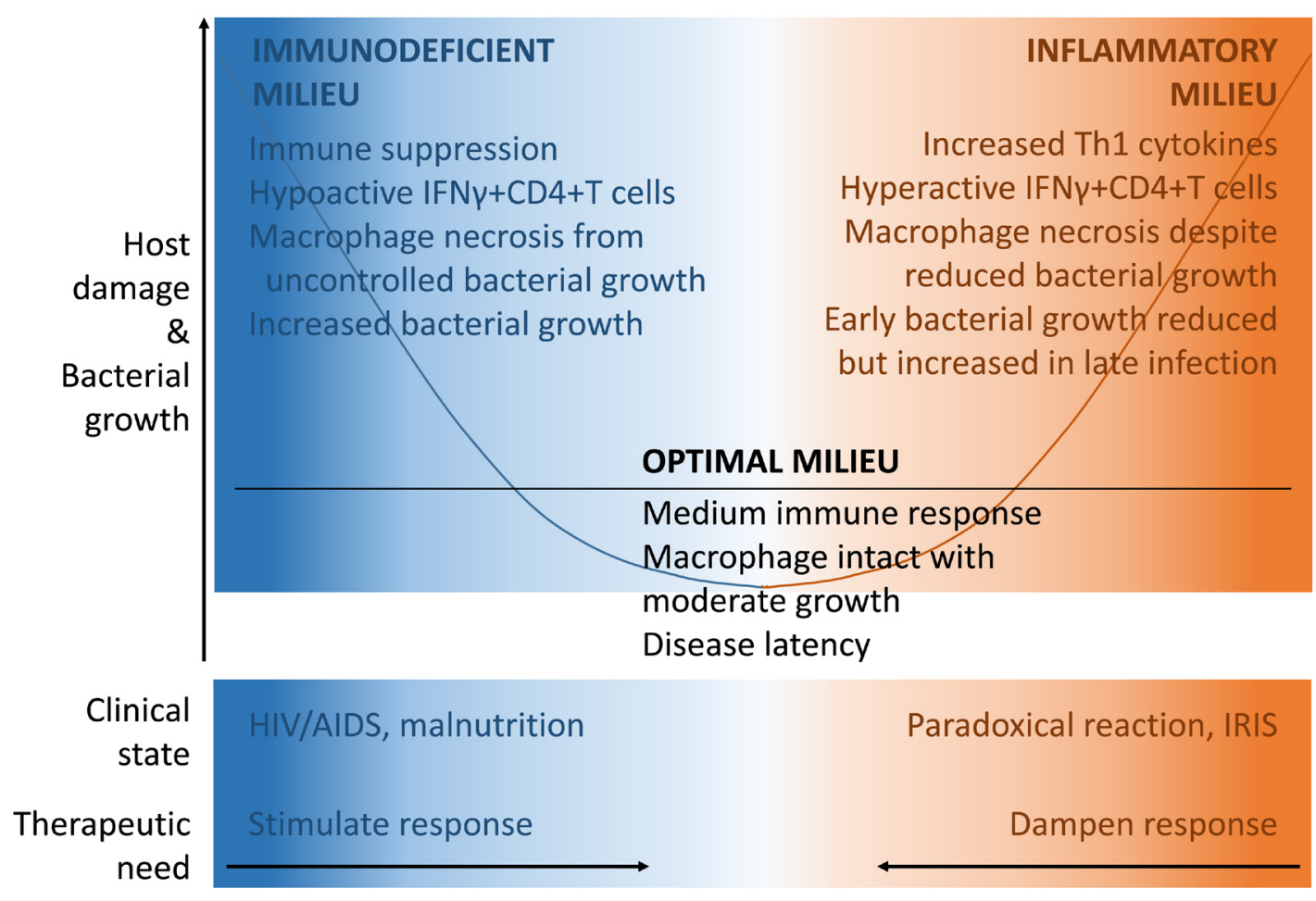

Figure 3. Outcomes of the host - M. tuberculosis interaction depicted by the basic parabola of the damage-response framework. On the left side of the parabola, shaded in blue, the immune system fails to limit mycobacterial growth and invasion which results in host damage. On the right side, shaded in red, the immune response is excessive and the resultant inflammation and host-damage. The proportion of the parabola lying below the black line represents disease latency, which is not associated with clinically evident host damage. On the blue side therapeutic interventions could be targeted at stimulating an immune response, whilst on the red side therapeutic interventions could aim to dampen immune response. 


\section{TBM diagnostics}

The field of TBM diagnostics has evolved rapidly in recent years with both complex and low-tech assays being explored in a variety of populations. Whilst progress has been made, no single assay can be used as a rule out test. The characteristics of CSF tests studied to date are summarized in Table 1.
Host-based diagnostic biomarkers

Traditional diagnostic techniques for TBM include CSF smear microscopy for acid fast bacilli (rapid and cheap but insensitive in most settings, 10-15\%) and CSF culture (improved sensitivity of $50-60 \%$ but results in 2-6 weeks with a biosafety lab level three requirement) ${ }^{3}$. Given the limitations of traditional,

\section{Table 1. Summary of TBM CSF Diagnostic Test Performance and Limitations.}

\begin{tabular}{|c|c|c|c|c|c|}
\hline Test & Sensitivity* & Specificity* & $\begin{array}{l}\text { Time to } \\
\text { Results }\end{array}$ & Strengths & Limitations \\
\hline AFB Smear & $10-34 \%$ & $95-100 \%$ & Hours & $\begin{array}{l}\text { Rapid, cheap, widely available, } \\
\text { specificity }\end{array}$ & Poor sensitivity in most settings \\
\hline Culture & $48-60 \%$ & $100 \%$ & $\begin{array}{l}2-6 \\
\text { weeks }\end{array}$ & $\begin{array}{l}\text { Sensitivity, excellent specificity, } \\
\text { antimicrobial resistance testing }\end{array}$ & $\begin{array}{l}\text { Slow, lab infrastructure, costly, inadequate } \\
\text { NPV }\end{array}$ \\
\hline $\begin{array}{l}\text { Adenosine } \\
\text { deaminase }\end{array}$ & $89 \%$ & $91 \%$ & Days & $\begin{array}{l}\text { Good sensitivity, low CSF volume } \\
\text { requirement }\end{array}$ & $\begin{array}{l}\text { Cost, lab infrastructure, false positives, } \\
\text { study heterogeneity, variable test } \\
\text { performance }\end{array}$ \\
\hline IGRA & $77 \%$ & $88 \%$ & Days & Sensitivity & $\begin{array}{l}\text { Cost, lab infrastructure, false positives, } \\
\text { indeterminate results, varied study } \\
\text { designs and cut-points }\end{array}$ \\
\hline Antibodies & $75-91 \%$ & $91-98 \%$ & Days & Sensitivity & $\begin{array}{l}\text { Variable study design, lack of commercial } \\
\text { assays, false positives, numerous different } \\
\text { targets }\end{array}$ \\
\hline $\begin{array}{l}\text { IL-13, VEGF, } \\
\text { cathelicidin } \\
\text { LL-37 }^{\text {a }}\end{array}$ & $52 \%$ & $95 \%$ & Days & $\begin{array}{l}\text { Sensitivity, low CSF volume } \\
\text { requirement }\end{array}$ & $\begin{array}{l}\text { Cost, lab infrastructure, requires } \\
\text { validation, technical expertise }\end{array}$ \\
\hline $\begin{array}{l}\text { IFNg, MPO, } \\
\text { VEGF }^{\mathrm{a}}\end{array}$ & $91 \%$ & $100 \%$ & Days & $\begin{array}{l}\text { Sensitivity, low CSF volume } \\
\text { requirement }\end{array}$ & $\begin{array}{l}\text { Cost, lab infrastructure, requires } \\
\text { validation, technical expertise }\end{array}$ \\
\hline $\begin{array}{l}\text { Traditional } \\
\text { NAAT }\end{array}$ & $68-82 \%$ & $100 \%$ & Days & Sensitivity, specificity & $\begin{array}{l}\text { Cost, lab infrastructure, many are } \\
\text { 'in-house' tests, variable study design, } \\
\text { variable targets, stringent operational } \\
\text { conditions, technical expertise }\end{array}$ \\
\hline $\begin{array}{l}\text { Xpert MTB/ } \\
\text { Rif }\end{array}$ & $40-70 \%$ & $98-100 \%$ & Hours & $\begin{array}{l}\text { Sensitivity, specificity, rapid, } \\
\text { ease of use, detects rifampin } \\
\text { resistance, widely distributed } \\
\text { platform }\end{array}$ & $\begin{array}{l}\text { Cost, inadequate NPV, variable study } \\
\text { design and performance }\end{array}$ \\
\hline Xpert Ultra & $47-95 \%$ & $100 \%$ & Hours & $\begin{array}{l}\text { Sensitivity, specificity, rapid, } \\
\text { ease of use, detects rifampin } \\
\text { resistance, widely distributed } \\
\text { platform }\end{array}$ & $\begin{array}{l}\text { Cost, inadequate NPV, variable study } \\
\text { design and performance }\end{array}$ \\
\hline CRISPR-MTB & $73 \%$ & $98 \%$ & Hours & $\begin{array}{l}\text { Low CSF volume, sensitivity, } \\
\text { specificity, isothermal }\end{array}$ & $\begin{array}{l}\text { Cost, lab infrastructure, stringent } \\
\text { operational use, technical expertise, } \\
\text { requires validation }\end{array}$ \\
\hline mNGS & $67 \%$ & $98-100 \%$ & $\begin{array}{l}\text { Days- } \\
\text { Weeks }\end{array}$ & $\begin{array}{l}\text { Can detect alternative } \\
\text { pathogens, sensitivity, specificity }\end{array}$ & $\begin{array}{l}\text { Cost, lab infrastructure, very stringent } \\
\text { operational use, technical expertise, } \\
\text { requires validation }\end{array}$ \\
\hline Alere TB LAM & $22-24 \%$ & $95 \%$ & Minutes & $\begin{array}{l}\text { Rapid, cost, heat stability, limited } \\
\text { lab expertise or infrastructure } \\
\text { requirements }\end{array}$ & $\begin{array}{l}\text { Sensitivity, intra-operative variability, } \\
\text { inadequate NPV }\end{array}$ \\
\hline $\begin{array}{l}\text { Fujifilm } \\
\text { SILVAMP } \\
\text { TB LAM }\end{array}$ & $52-74 \%$ & $98 \%$ & 1 hour & $\begin{array}{l}\text { Rapid, sensitivity, heat stability, } \\
\text { limited lab expertise or } \\
\text { infrastructure requirements }\end{array}$ & $\begin{array}{l}\text { Cost, intra-operative variability, } \\
\text { inadequate NPV }\end{array}$ \\
\hline
\end{tabular}

*All sensitivity and specificity values are approximate, based on current literature with the understanding that variability occurs between studies and with local disease prevalence.

a: Reported values are for paediatric patients only

TBM: Tuberculous meningitis; AFB: acid-fast bacilli; NPV: negative predictive value; IGRA: interferon gamma release assay; IL: interleukin; VEGF: vasoactive endothelial growth factor; IFNg: interferon gamma; MPO: myeloperoxidase; NAAT: nucleic acid amplification tests; Xpert: GeneXpert MTB/Rif; Xpert Ultra: GeneXpert MTB/Rif Ultra; CRISPR-MTB: Clustered regularly interspaced palindromic repeat associated proteins - Mycobacteria tuberculosis; mNGS: metagenomic next generation sequencing; LAM: lipoarabinomannan; 
diagnostic tests for TBM that focus on bacillary detection, there is interest in the utilization of host-based diagnostic biomarkers for diagnosis of TBM, Figure 4. Adenosine deaminase (ADA), produced by lymphocytes, is an important regulator of follicular helper T-cells. ADA is commonly used for diagnosis of TB from other, typically extra-pulmonary locations and numerous studies have considered ADA for diagnosis of $\mathrm{TBM}^{54}$. One 2017 meta-analysis found ADA to have a pooled sensitivity of $89 \%$ (95\% CI $84-92 \%$ ) with pooled specificity $91 \%(95 \% \mathrm{CI}, 87-93 \%)^{54}$. Yet ADA use for TBM diagnosis has been limited by the high cost of the test, required sophisticated lab infrastructure, study heterogeneity, inadequate negative predictive values, and variable test performance.

A number of studies have considered unstimulated CSF interferon gamma (IFN- $\gamma$ ) levels as a diagnostic test, in general, a high number of false positive results has limited the utility of CSF IFN- $\gamma^{55,56}$. For instance, in one study of 39 controls $(\mathrm{n}=12$ viral, $\mathrm{n}=16$ purulent, $\mathrm{n}=11$ cryptococcal meningitis) and 30 subjects with TBM while median IFN- $\gamma$ levels were higher amongst subjects with TBM, diagnostic accuracy was inadequate $^{56}$. At the strongest cut-point $(81 \mathrm{pg} / \mathrm{mL})$ determined by receiver operator curve analysis, positive predictive value was only $81 \%$ with positive results occurring in $2 / 12$ (17\%) with viral meningitis, 3/16 (19\%) with purulent meningitis, and $1 / 11(9 \%)$ with cryptococcal meningitis ${ }^{56}$.
Interferon gamma release assays (IGRAs) are commonly used to infer LTBI. A 2016 meta-analysis of six studies performing CSF IGRA's found a pooled sensitivity and specificity of $77 \%$ (95\% CI 69\%-84\%) and 88\% (95\% CI 74\%-95\%), respectively, for TB meningitis, though reference standards varied by study $^{57}$. Limitations of IGRA include high cost, the need for advanced lab infrastructure, frequent "indeterminate" results, and false positives associated with other causes of meningitis. Additional host biomarkers including delta-like ligand 1, vitamin D binding protein, and fetuin have been evaluated in CSF though none were found to have satisfactory performance ${ }^{58}$. Numerous CSF antibodies to M.tb in CSF has also been evaluated. Huang and colleagues found pooled sensitivities of $91 \%$ (95\% CI 71-98\%) for anti-M37Ra across five studies, $84 \%(95 \%$ CI 71-92\%) for anti-antigen-5 across eight studies, and $84 \%$ (95\% CI 71-92\%) across 12 studies for anti-M37Rv, again using a variety of reference standards (making the pooled estimates somewhat flawed $)^{59}$. Use of blood antibody assays are discouraged for the diagnosis of TB, and their utility in CSF is limited by heterogeneity and the lack of a uniform reference standard across research studies as well as a lack of commercial assays.

Though on the surface, many of these markers look to have promise, uptake has been limited. Heterogeneity in study design and widely variable study performance has limited the consensus regarding the utilities for most host-based tests. Further, many

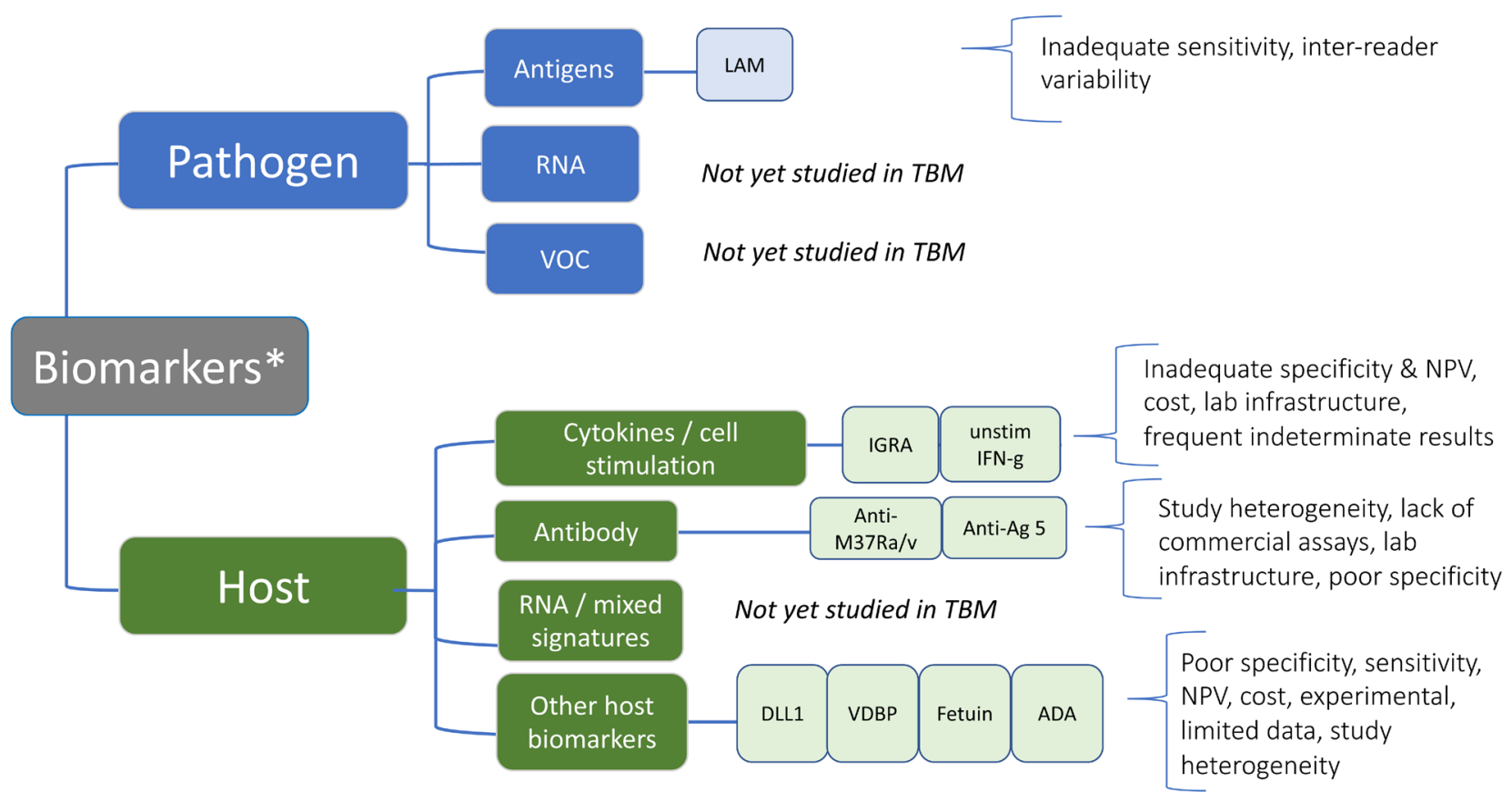

Figure 4. Novel Host and Pathogen biomarkers for diagnosis of tuberculous meningitis ${ }^{54-60}$. LAM = lipoarabinomannan, RNA $=$ riboneucleic acid, VOC = volatile organic chemicals, IGRA = inferferon gamma resease assay, DLL1 = delta-like ligand $1, \mathrm{VDBP}=$ vitamin $d$ binding protein, ADA = adenosine deaminase. * This image focuses only on novel host or TB biomarkers for diagnosis of TBM and does not incorporate traditional tools such as culture or AFB smear, or newer nucleic acid amplification tests in use commonly such as GeneXpert or GeneXpert Ultra, or experimental techniques such as metagenomic next generation sequencing. 
of these tests require sophisticated laboratory infrastructure, are costly, and in some cases are not commercially available. None of these CSF tests are routinely used and as far as the authors are aware, none are actively being studied further.

In the field of pulmonary tuberculosis, host RNA transcriptomic signatures have been leveraged to predict incipient and active tuberculosis with moderate short-term $(<3$ month) sensitivity $(41-81 \%)^{61}$. A whole blood 3-gene signature (GBP5, DUSP3, KLF2) has been shown to accurately differentiate active pulmonary tuberculosis from healthy controls (area under receiver operator curve, AUC 0.90), latent TB infection (AUC 0.88 ) and other diseases ${ }^{62}$ (AUC 0.84). Whether this 3-gene signature in whole blood has diagnostic value in TBM, whereby the inflammation can be compartmentalised to the CNS, remains to be investigated. An ongoing study in Uganda is adopting a machine learning approach to develop a classifier that categorises patients as TBM or not-TBM based on their CSF RNA signature. In CSF, genes predominantly predicted TBM (FTL, NFKBIA, SOD2, GBP5) and the classifier demonstrated good sensitivity and specificity (unpublished data).

\section{Biomarkers in children}

The often-dismal outcome of TBM is contributed to by delayed diagnosis and/or initiation of treatment, especially in high burden settings ${ }^{4}$. Currently available diagnostic test performance is especially poor in young children with TBM. Thus, diagnosis of childhood TBM is mostly based on a combination of clinical findings, CSF analysis and radiological findings ${ }^{63}$. Even so, there are often multiple missed opportunities prior to a diagnosis of childhood $\mathrm{TBM}^{64}$. Since it can be challenging to identify bacilli in paediatric extrapulmonary TB, the use of host or pathogen biomarkers to aid diagnosis is being explored. Host biomarker-based tests have shown promise in extrapulmonary $\mathrm{TB}$ outside of the CNS and therefore have potential applications in $\mathrm{TBM}^{65}$. Recent technological advances have made it possible to screen for many biomarkers in as little as $3 \mu \mathrm{l}$ of sample using the Luminex multiplex cytokine beaded arrays, albeit in research context currently, rather than routine clinical practice.

In a study evaluating disease-specific CSF biomarkers of paediatric TBM, a combination of 28 cytokines and soluble mediators were assessed; 27 host biomarkers by Luminex multiplex bead array technology (Bio-Rad Laboratories) and cathelicidin LL-37 concentration by using an enzyme-linked immunosorbent assay (ELISA) kit (USCN Life Science). A three-marker CSF biosignature comprising IL-13, VEGF and cathelicidin LL-37, diagnosed childhood TBM with a sensitivity of $52 \%$, specificity of $95 \%$, with positive and negative predictive values of $91 \%$ and $66 \%$ respectively. Cut-off values for VEGF, IL-13 and cathelicidin LL-37 were $42.92 \mathrm{pg} / \mathrm{mL}, 37.26 \mathrm{pg} / \mathrm{mL}$ and $3221.01 \mathrm{pg} / \mathrm{mL}$ respectively ${ }^{15}$. Further evaluation of this three-marker CSF biosignature in a different cohort revealed positive and negative predictive values of $90 \%$ and $59.5 \%$ respectively, however with different cut-off values for VEGF, IL-13 and cathelicidin LL-37 of $9.4 \mathrm{pg} / \mathrm{ml}, 524.9 \mathrm{pg} / \mathrm{ml}$ and optical density of 0.045 respectively ${ }^{66}$. In this study investigating
69 potentially-useful host biomarkers for childhood TBM (23 children with TBM and 24 controls) comprising a combination of cytokines and soluble mediators in CSF (cathelicidin LL-37 by using an ELISA kit purchased from Elabscience Biotechnology Inc. (catalog \#E-EL-H2438) and the rest by Luminex assay), 28 proteins including IFN- $\gamma$, TNF- $\alpha$, MPO, MMP-8, MMP-9, MIP-4 and CXCL9 amongst others, when analysed individually, showed areas under the receiver-operating curve (AUC) $\geq 0.80$. When combined, biomarkers IFN- $\gamma$, MPO and VEGF showed good accuracy (AUC $=0.97$, up to $91.3 \%$ sensitivity and up to $100 \%$ specificity), as well as ICAM-1, MPO, CXCL8, and IFN- $\gamma$ (AUC of 0.97, up to $87.0 \%$ sensitivity and up to $95.8 \%$ specificity). Cut-off values for VEGF, IFN- $\gamma$, MPO, ICAM-1 and CXCL8 were $>9.4 \mathrm{pg} / \mathrm{ml}$, $>99.5 \mathrm{pg} / \mathrm{ml},>25823.0 \mathrm{pg} / \mathrm{ml},>1372.0 \mathrm{pg} / \mathrm{ml}$ and $>394.8 \mathrm{pg} / \mathrm{ml}$, respectively ${ }^{66}$.

Limitations of the studies assessing CSF host biomarkers in childhood TBM include relatively small sample size, and therefore few children with confirmed TBM, confirmed meningitis due to other pathogens, and confirmed HIV co-infection. External validation is a necessity in order to generalize the clinical usefulness of the prediction model in an independent group of patients. the potential of CSF-based biosignatures, a further limitation is the invasive nature of CSF collection, and blood or urine-based inflammatory biosignatures require exploration. In a study evaluating serum biomarkers, the combination of CRP, IFN- $\gamma$, IP-10, CFH, Apo-A1 and SAA showed moderate diagnostic accuracy for clinically-defined TBM, including both 'definite' and 'probable' TBM (AUC of 0.75 , sensitivity of $69.6 \%$ and specificity of $62.5 \%$ ). A three-biomarker combination of adipsin, $\mathrm{A} \beta 42$ and IL-10 showed improved accuracy (AUC of 0.84 , sensitivity of $82.6 \%$ and specificity of $75.0 \%$ ). Cut-off values for CRP, IFN- $\gamma$, IP-10, CFH, Apo-A1, SAA, adipsin, A $\beta 42$ and IL-10 were $>80721.0 \mathrm{ng} / \mathrm{ml},<61.5 \mathrm{pg} / \mathrm{ml},<57.2 \mathrm{pg} / \mathrm{ml},>350185.0 \mathrm{ng} / \mathrm{ml}$, $>287512.0 \mathrm{ng} / \mathrm{ml},>59894.0 \mathrm{ng} / \mathrm{ml},<2393.0 \mathrm{ng} / \mathrm{ml},<278.4 \mathrm{pg} / \mathrm{ml}$ and $<7.0 \mathrm{pg} / \mathrm{ml}$, respectively. Although sample size was small, these biomarkers warrant further exploration ${ }^{67}$.

\section{Pathogen-based diagnostics}

The absence of a perfect gold standard for use in TBM diagnostic studies means that the results must be interpreted with an awareness of the pros and cons of the reference standard used. The 2010 uniform TBM case definition which defines cases as 'definite', 'probable', 'possible' or 'not TBM' is the most standardised tool to use when defining a case definition ${ }^{63}$. This case definition was derived by expert consensus rather than being data-driven and, although designed to be applicable to any age, HIV infection status or geographical setting, may perform better in some contexts than others. In HIV-negative populations a reference standard of 'definite, probable or possible' is often used, however in PLWHIV including 'possible' in the reference standard can be imprecise due to the wide variety of infectious and non-infectious aetiologies that can fall into this category. We do strongly advocate the use of the case definition to standardise results, allow for greater comparison between studies and meta-analysis of data; use of other standards must be interpreted with a degree of caution. 


\section{Nucleic-acid amplification tests}

To address the limitations of conventional microscopy and culture techniques, NAATs have emerged as important tools for rapid and accurate diagnosis of $\mathrm{TBM}^{44}$. A recent meta-analysis evaluating NAATs in TBM reported heterogeneity in results with a pooled sensitivity of $82 \%$ against culture and $68 \%$ against a clinical reference standard ${ }^{68}$. This variability, especially in in-house NAATs, is subject to difference in volume of sample, method of extraction, choice of targets used, presence of inhibitors in the sample and lack of optimal reference standard. Traditional NAATs require expensive equipment, stringent operational conditions and technical expertise limiting their use in routine clinical practice in lower-resource, high endemic settings. To circumvent these challenges, loop mediated isothermal amplification (LAMP) assays were developed and can be conveniently carried out under isothermal conditions in an ordinary laboratory water bath or heating block within one hour. Though LAMP has outperformed PCR in an Indian study on $\mathrm{TBM}^{69}$, the assay is still in its infancy and needs further validation. Another method to potentially reduce the overall cost of NAAT would be to utilize magnetic bead assay technology, thus obviating the need of gel electrophoresis system or expensive dyes.

Xpert is a rapid (90 min run-time) fully-automated cartridgebased real-time PCR assay that detects the presence of M.tb complex DNA, as well as $r p o B$ gene mutations responsible for rifampicin resistance. The pooled sensitivity and specificity of Xpert against culture in 33 studies on TBM, was $71.1 \%$ and $98 \%$, respectively ${ }^{70}$. Xpert has been shown to significantly increase microbiological confirmation of TBM in Uganda over a 6.5-year period but its impact on clinical outcomes in unknown ${ }^{71}$. Individual studies have also found inferior performance for Xpert compared to multiplex $\mathrm{PCR}^{72}$ or Amplicor assay $^{73}$ in diagnosing TBM although these results have not been confirmed. The next generation, GeneXpert MTB/Rif Ultra (Ultra) has an 8-fold lower limit of detection than Xpert $(16 \mathrm{CFU} / \mathrm{ml}$ versus $113 \mathrm{CFU} / \mathrm{ml}$ ) attributable to a larger chamber allowing double the volume of sample to reach the PCR reaction and two additional DNA probes (IS1081 and IS6110) ${ }^{74}$. In a Ugandan study of Ultra using cryopreserved CSF, alongside MGIT culture and Xpert, Ultra demonstrated a sensitivity of 95\% against a composite microbiological reference and $70 \%$ against probable/definite TBM in comparison to $45 \%$ and $43 \%$, respectively for each Xpert and culture ${ }^{75,76}$. In 2017, Ultra was endorsed by the WHO as the best initial test for TBM and is being rolled out currently worldwide, superseding $\mathrm{Xpert}^{77}$.

In January 2020, two larger prospective studies evaluating Ultra were published. In the Ugandan study, 204 (96\% HIV-positive) adults with suspected meningitis had CSF Xpert Ultra performed. Compared with a reference of definite/probable TBM, test sensitivities were $77 \%$ (95\% CI $63-87 \%$ ) for Ultra, $56 \%(95 \%$ CI $44-70 \%$ ) for Xpert, and $61 \%$ (95\% CI $45-76 \%$ ) for mycobacterial culture ${ }^{78}$. In this study 'possible TBM' cases were not included in the reference standard as this category is non-specific in HIV co-infection due to concomitant infectious and non-infectious brain pathologies associated with advanced immunosuppression. In the second study,
Donovan et al. employed a different study design and randomised 205 Vietnamese adults (15\% HIV co-infected) with meningitis to either Ultra or Xpert testing. Against a reference standard of definite, probable, or possible TBM, test sensitivities were $47 \%$ (95\%CI, $34-60 \%$ ) for Ultra, 40\% (95\%CI, $28-53 \%$ ) for Xpert, and $48 \%(95 \% \mathrm{CI}, 38-58 \%)$ for mycobacterial culture $^{79}$. Specificity of Ultra for TBM diagnosis was high in both studies. The sensitivity of Ultra statistically superior to that of Xpert in Uganda but not in a Vietnamese predominantly HIV-negative population. How can we rationalise and interpret these differing results? Firstly, diagnostic tests cannot be expected to perform identically in all settings. Differences in tested CSF volume, CSF processing, HIV co-infection, genetics influencing host response to M.tb, and M.tb lineages (the number of copies of IS1081 and IS6110 genes varies by lineage) could all contribute to these different results, as could the differences in study design (e.g. head-to-head comparison versus randomizing samples) and smear microscopy sensitivity and reference standards used. Secondly, and most importantly, regardless of the differences in the exact performance of Ultra, the key point is that while Ultra demonstrates some improvement on the performance of Xpert, its negative predictive value is not sufficiently high to exclude TBM when the result is negative.

Another commercial NAAT, the MTBDRplus assay, has been evaluated only in few cases of TBM and needs further validation ${ }^{80}$. Accurate and rapid detection of drug resistance is another challenge, rifampicin resistance detection by Xpert has imperfect sensitivity (93\%) and where detected and ideally requires confirmation by sequencing or culture ${ }^{72,81}$. Ultra uses melt curve analysis to improve detection of rifampicin resistance but both are about $95 \%$ sensitive $^{82,83}$. Ultra will not be able to adequately define rifampin resistance in samples with a low quantity of bacilli (trace category positive) ${ }^{75}$. In summary NAATs, are a major diagnostic advance but they cannot yet fully replace culture methods. Ultra is too insensitive to rule out TBM, and like Xpert, should be considered as the first test and not the last in TBM diagnosis ${ }^{84}$. Ultra is an important step in the right direction but the result should be considered in the context of the clinical probability of $\mathrm{TBM}^{85}$.

CRISPR-MTB and metagenomic next generation sequencing. Clustered regularly interspaced palindromic repeat (CRISPR) associated proteins (Cas) have the ability to cleave DNA at specific sites and are being used widely in gene-editing and more recently in infectious disease diagnostics. When combined with DNA amplification, the CRISPR system can detect nucleic acid molecules at extremely low abundance. There is one recent report of utilizing the CRISPR system for detection of M.tb (CRISPR-MTB). The study included $26 \mathrm{CSF}$ specimens and found CRISPR-MTB to have a sensitivity of $73 \%$ compared to $54 \%$ for Xpert and $23 \%$ for culture against a reference standard of 'clinical TBM' as determined by the physician based on clinical presentation imaging and response to TB therapy. The specificity of the test was $98 \%$ when tested against 63 non-TB cases. CRISPR-MTB is isothermal and can be performed in under 2 hours using only $500 \mu \mathrm{l}$ of CSF. CRISPR-MTB remains to 
be tested against Ultra and requires a higher level of laboratory expertise, resources, and time than the Xpert platform but may be an advance in TB diagnostics if these findings can be confirmed in other settings with more standardized reference standards ${ }^{86}$.

Metagenomic next generation sequencing (mNGS) is a rapidly developing technology that has proved useful in determining aetiologies for CNS infections that have evaded detection by conventional techniques. Further, mNGS, as opposed to organism-specific molecular tests has the ability to detect any low abundance infection with a single test ${ }^{87}$. A recent small study applied mNGS to stored CSF samples from 23 TBM cases and found a sensitivity of $67 \%(8 / 12)$ against a reference standard of definite TBM, higher than AFB stain $(33 \%, 4 / 12)$, PCR $(25 \%$, $3 / 12)$ and culture $(8 \%, 1 / 12)^{88}$. Paucibacillary conditions such as TBM where the bacillary load may fall below the LOD of commercial NAATs, or where mutations exist around specific PCR primer binding sites may find particular use for mNGS. Targeted enrichment of low abundance genes with Finding Low Abundance Sequences by Hybridization (FLASH), a novel CRISPR-Cas9 technology can increase DNA read abundance by up to $10^{5}$-fold before sequencing occurs ${ }^{89}$. Combining FLASH and mNGS technologies could improve detection of TB DNA and associated antimicrobial resistance mutations mutations ${ }^{90}$. A first pilot of FLASH technology in TB demonstrated up to a 100-fold increase in TB read abundance, detection of $6 / 6$ cases of TBM positive with Ultra and detection of an additional case of TBM that had been missed by Xpert, Ultra and MGIT culture $^{91}$. Here again, large studies need to be performed to better understand this technology's performance and the cost, laboratory infrastructure, and degree of expertise will need to be improved upon to permit widespread usage.

Pathogen-based biomarkers. A urine lateral flow assay (LFA) that detects M.tb lipoarabinomannan (TB-LAM), a $17 \mathrm{kDa}$ glycolipid found in the outer cell wall of MTB, has recently been recommended by the World Health Organization for the diagnosis of $\mathrm{HIV}$-associated $\mathrm{TB}$ in HIV-positive inpatients (Alere Determine TB-LAM, Abbott, Chicago, USA). The unique characteristic of the test is that its sensitivity increases as CD4 T-cell count falls, with a sensitivity of $56 \%$ in those with CD4 $<100$ cells $/ \mathrm{ml}^{60}$. Yet, in CSF, despite some initial optimism related to an autopsy-based study in Uganda, the Alere TB-LAM has shown poor sensitivity on lumbar CSF in Uganda ${ }^{92,93}$, along with a larger Zambian study which examined culture positive TBM in Zambia (TB-LAM sensitivity $22 \%(23 / 105))^{92,94,95}$. The Alere TB-LAM is also limited by its susceptibility to individual reader interpretation of the darkness of the test line compared to the reference card (Figure 4). A novel LAM assay (Fujifilm SILVAMP TB-LAM, Fujifilm, Japan) is able to detect concentration of LAM at approximately 30-fold lower than Alere TB-LAM due to design differences, including a silver amplification step and gives a result in one hour ${ }^{96}$. The Fujifilm LAM was recently tested on the CSF of 101 predominantly HIVpositive adults with suspected TBM. FujiLAM sensitivity was
$74 \%(25 / 34,95 \%$ CI 56-87\%) versus definite TBM and 52\% (30/58, 95\%CI 38-65\%) versus probable/definite TBM. The FujiLAM assay may play a role in reducing time to treatment where the Xpert Ultra platform is not immediately accessible or where clinical suspicion of TBM is high despite a negative CSF Ultra result. The sensitivity of FujiLAM was superior to Alere LAM $(50 \%$ versus $14 \%, \mathrm{p}<0.01$ in those tested with both assays $)^{97}$.

\section{Clinical prediction rules}

Work is underway to develop a more accurate multivariable clinical prediction rule derived from large international cohorts using individual patient data ${ }^{98}$. The hope is that a data-driven scoring system will be developed for use in a range of clinical settings by using common, readily available clinical or laboratory parameters to aide in clinical decision making.

\section{Discussion}

In the last five years, the pathogenesis of TBM has been better elucidated, in part thanks to detailed immunological studies on clinical samples preemptively stored during clinical trials. These advances highlight the importance of collecting and storing samples appropriately for future research to maximize scientific outputs, as highlighted in the paper on sampling strategies in this collection. HIV infection is a major predictor of mortality in TBM and advanced HIV infection (CD4 T cell count $<150$ cell/ $\mu \mathrm{l}$ ) appears to drive a dysregulated, hyperinflammatory phenotype with very poor outcomes. In HIV-endemic sub-Saharan African settings around $90 \%$ of all adult TBM occurs amongst HIV-positive individuals ${ }^{71,95}$, often with either untreated advanced HIV or having recently initiated ART - both driving a hyperinflammatory response. In Vietnamese adults with TBM, LTA4H genotype is a strong predictor of mortality though this finding was not duplicated in Indonesia.

Recent insights have shown that neutrophils play a significant role in the immunopathogenesis of TBM, and that both a paucity and an excess of inflammation can be equally damaging in TBM. It has become increasingly clear that a 'one-size-fits-all' approach is too simplistic in TBM treatment, as in other infections such as pulmonary TB and sepsis ${ }^{99,100}$. The damage-response framework may provide a useful structure for understanding host-pathogen interactions in TBM, illustrating how immune response could be exploited for therapeutic purposes. Additional anti-inflammatory therapy with aspirin ${ }^{17,101}$ or more targeted immunotherapy could have a role in persons with an excessive inflammatory response; whilst individuals with an inadequate response might do better without corticosteroid treatment or might even benefit from immunomodulating therapy to boost their immune response ${ }^{102}$. Future trials of novel specific hostdirected therapies are needed and must include immune markers to allow for post-hoc identification of subgroups benefitting from the initiated therapy. Because of the lack of correlation between blood and CSF compartments we advocate inclusion of both blood and CSF markers when studying adjuvant therapies. 
The field of TBM diagnosis is rapidly evolving with GeneXpert MTB/Rif Ultra being the most promising test to date for diagnosis of TBM. Ultra is rapid and has potential to confirm more cases of TBM at lower bacillary loads, though whether this will improve outcomes remains to be determined. Most importantly, Ultra does not appear to have adequate predictive value to 'rule-out' TBM and so it cannot meet the potential of an ideal TBM diagnostic test to avoid long, toxic TBM therapy in persons without TBM. Novel sequencing technologies hold potential to provide increased understanding of pathogen genomics and behavior and further illuminate host response, which may in turn lead to novel diagnostic and therapeutic targets. Sequencing technologies are increasingly available in TB endemic settings but will need further improvements in affordability and speed in addition to more data on accuracy to unlock their potential as diagnostic tools for TBM. It is now a realistic hope that a test (or set of tests) will one day be available that will be able to confirm or rule out TBM, provide M.tb resistance information, and direct clinicians to targeted, adjunctive host-directed therapy within hours.

\section{Acknowledgements}

Tuberculosis Meningitis International Research Consortium

Rob E. Aarnoutse; Suzanne T. B. Anderson; Nathan C. Bahr; Nguyen D. Bang; David R. Boulware; Tom Boyles; Lindsey H. M. te Brake; Satish Chandra; Felicia C. Chow; Fiona V. Cresswell; Reinout van Crevel; Angharad G. Davis; Sofiati Dian; Joseph Donovan; Kelly E. Dooley; Anthony Figaji; A. Rizal Ganiem; Ravindra Kumar Garg; Diana M. Gibb; Raph L. Hamers; Nguyen T. T. Hiep; Darma Imran; Akhmad Imron; Sanjay K. Jain; Sunil K. Jain; Byramee Jeejeebhoy; Jayantee Kalita; Rashmi Kumar; Vinod Kumar; Arjan van Laarhoven; Rachel P-J. Lai; Abi Manesh; Suzaan Marais; Vidya Mave; Graeme Meintjes; David B. Meya; Usha K. Misra; Manish Modi; Alvaro A. Ordonez; Nguyen H. Phu; Sunil Pradhan; Kameshwar Prasad; Alize M. Proust; Lalita Ramakrishnan; Ursula Rohlwink; Rovina Ruslami; Johannes F. Schoeman; James A. Seddon; Kusum Sharma; Omar Siddiqi; Regan S. Solomons; Nguyen T. T. Thuong; Guy E. Thwaites; Ronald van Toorn; Elizabeth W. Tucker; Sean A. Wasserman; Robert J. Wilkinson.
1. Wilkinson RJ, Rohlwink U, Misra UK, et al.: Tuberculous meningitis. Nat Rev Neurol. 2017; 13(10): 581-598. PubMed Abstract | Publisher Full Text

2. Davis AG, Rohlwink UK, Proust A, et al.: The pathogenesis of tuberculous meningitis. J Leukoc Biol. 2019; 105(2): 267-80.

PubMed Abstract | Publisher Full Text | Free Full Text

3. Bahr NC, Meintjes G, Boulware DR: Inadequate diagnostics: the case to move beyond the bacilli for detection of meningitis due to Mycobacterium tuberculosis. J Med Microbiol. 2019; 68(5): 755-60.

PubMed Abstract | Publisher Full Text

4. Chiang SS, Khan FA, Milstein MB, et al.: Treatment outcomes of childhood tuberculous meningitis: a systematic review and meta-analysis. Lancet Infect Dis. 2014; 14(10): 947-57.

PubMed Abstract | Publisher Full Text

5. Gupta N, Kumar R, Agrawal B: New Players in Immunity to Tuberculosis: The Host Microbiome, Lung Epithelium, and Innate Immune Cells. Front Immunol. 2018; 9: 709 .

PubMed Abstract | Publisher Full Text | Free Full Text

6. Turner RD, Chiu C, Churchyard GJ, et al:: Tuberculosis Infectiousness and Host Susceptibility. J Infect Dis. 2017; 216(suppl_6): S636-S43. PubMed Abstract | Publisher Full Text | Free Full Text

7. Torrelles JB, Schlesinger LS: Integrating Lung Physiology, Immunology, and Tuberculosis. Trends Microbiol. 2017; 25(8): 688-97. PubMed Abstract | Publisher Full Text | Free Full Text

8. Donald PR, Schaaf HS, Schoeman JF: Tuberculous meningitis and miliary tuberculosis: the Rich focus revisited.J Infect. 2005; 50(3): 193-5. PubMed Abstract | Publisher Full Text

9. Dekker $\mathrm{G}$, Andronikou $\mathrm{S}$, van Toorn $\mathrm{R}$, et al.: MRI findings in children with tuberculous meningitis: a comparison of HIV-infected and non-infected patients. Childs Nerv Syst. 2011; 27(11): 1943-9. PubMed Abstract | Publisher Full Text

10. Wallgren A: Some aspects of tuberculous meningitis and the possibility of its prevention. J Pediatric. 1934; 5(3): 291-8. Publisher Full Text

11. Marais S, Pepper DJ, Marais BJ, et al.: HIV-associated tuberculous meningitis--diagnostic and therapeutic challenges. Tuberculosis. 2010; 90(6): 367-74.

PubMed Abstract | Publisher Full Text

12. Rich AR, HA M: The pathogenesis of tuberculous meningitis. Bull Johns Hopkins Hosp. 1933; 52: 413-29.

13. Simmons $\mathrm{CP}$, Thwaites GE, Quyen NT, et al.: Pretreatment intracerebral and peripheral blood immune responses in Vietnamese adults with tuberculous meningitis: diagnostic value and relationship to disease severity and outcome. J Immunol. 2006; 176(3): 2007-14. PubMed Abstract | Publisher Full Text

14. Donald PR, Schoeman JF, Beyers N, et al.: Concentrations of interferon gamma, tumor necrosis factor alpha, and interleukin-1 beta in the cerebrospinal fluid of children treated for tuberculous meningitis. Clin Infect Dis. 1995; 21(4): 924-9.

PubMed Abstract | Publisher Full Text

15. Visser DH, Solomons RS, Ronacher $\mathrm{K}$, et al.: Host immune response to tuberculous meningitis. Clin Infect Dis. 2015; 60(2): 177-87. PubMed Abstract | Publisher Full Text

16. Thuong NTT, Heemskerk D, Tram TTB, et al.: Leukotriene A4 Hydrolase Genotype and HIV Infection Influence Intracerebral Inflammation and Survival From Tuberculous Meningitis. J Infect Dis. 2017; 215(7): 1020-8. PubMed Abstract | Publisher Full Text | Free Full Text

17. Mai NT, Dobbs N, Phu NH, et al.: A randomised double blind placebo controlled phase 2 trial of adjunctive aspirin for tuberculous meningitis in HIV-uninfected adults. elife. 2018; 7: pii: e33478. PubMed Abstract | Publisher Full Text | Free Full Text

18. Colas RA, Nhat LTH, Thuong NTT, et al.: Proresolving mediator profiles in cerebrospinal fluid are linked with disease severity and outcome in adults with tuberculous meningitis. FASEB J. 2019; 5: fj201901590R. PubMed Abstract | Publisher Full Text

19. van Laarhoven A, Dian S, Ruesen C, et al: Clinical Parameters, Routine Inflammatory Markers, and LTA4H Genotype as Predictors of Mortality Among 608 Patients With Tuberculous Meningitis in Indonesia. J Infect Dis. 2017; 215(7): 1029-39. PubMed Abstract | Publisher Full Text

20. van Laarhoven A, Dian S, van Dorp S, et al.: Immune cell characteristics and cytokine responses in adult HIV-negative tuberculous meningitis: an observational cohort study. Sci Rep. 2019; 9(1): 884. PubMed Abstract | Publisher Full Text | Free Full Text

21. Campo M, Randhawa AK, Dunstan S, et al.: Common polymorphisms in the CD43 gene region are associated with tuberculosis disease and mortality. Am J Respir Cell Mol Biol. 2015; 52(3): 342-8. PubMed Abstract | Publisher Full Text | Free Full Text

22. Horne DJ, Randhawa AK, Chau TT, et al.: Common polymorphisms in the PKP3-SIGIRR-TMEM16J gene region are associated with susceptibility to tuberculosis. J Infect Dis. 2012; 205(4): 586-94. PubMed Abstract | Publisher Full Text | Free Full Text

23. Tobin DM, Roca FJ, Oh SF, et al.: Host genotype-specific therapies can optimize the inflammatory response to mycobacterial infections. Cell. 2012; 148(3): 434-46.

PubMed Abstract | Publisher Full Text | Free Full Text

24. Tobin DM, Vary JC Jr, Ray JP, et al.: The Ita4h locus modulates susceptibility to 
mycobacterial infection in zebrafish and humans. Cell. 2010; 140(5): 717-30. PubMed Abstract | Publisher Full Text | Free Full Text

25. Donovan J, Phu NH, Thao LTP, et al.: Adjunctive dexamethasone for the treatment of HIV-uninfected adults with tuberculous meningitis stratified by Leukotriene A4 hydrolase genotype (LAST ACT): Study protocol for a randomised double blind placebo controlled non-inferiority trial [version 1; peer review: 2 approved]. Wellcome Open Res. 2018; 3: 32.

PubMed Abstract | Publisher Full Text | Free Full Text

26. van Laarhoven A, Dian S, Aguirre-Gamboa R, et al.: Cerebral tryptophan metabolism and outcome of tuberculous meningitis: an observational cohort study. Lancet Infect Dis. 2018; 18(5): 526-35.

PubMed Abstract | Publisher Full Text

27. Thao LTP, Heemskerk AD, Geskus RB, et al.: Prognostic Models for 9-Month Mortality in Tuberculous Meningitis. Clin Infect Dis. 2018; 66(4): 523-32. PubMed Abstract | Publisher Full Text | Free Full Text

28. Thwaites GE, Nguyen DB, Nguyen HD, et al.: Dexamethasone for the treatment of tuberculous meningitis in adolescents and adults. $N$ EnglJ Med. 2004; 351(17): 1741-51.

PubMed Abstract | Publisher Full Text

29. Marais S, Wilkinson KA, Lesosky M, et al.: Neutrophil-associated central nervous system inflammation in tuberculous meningitis immune reconstitution inflammatory syndrome. Clin Infect Dis. 2014; 59(11): 1638-47. PubMed Abstract | Publisher Full Text | Free Full Text

30. Marais S, Lai RPJ, Wilkinson KA, et al.: Inflammasome Activation Underlying Central Nervous System Deterioration in HIV-Associated Tuberculosis. J Infect Dis. 2017; 215(5): 677-86.

PubMed Abstract | Publisher Full Text | Free Full Text

31. Thuong NTT, Thwaites GE: Treatment-Associated Inflammatory Deterioration in Tuberculous Meningitis: Unpicking the Paradox. J Infect Dis. 2017; 215(5): 665-7.

PubMed Abstract | Publisher Full Text | Free Full Text

32. Rohlwink UK, Mauff K, Wilkinson KA, et al.: Biomarkers of Cerebral Injury and Inflammation in Pediatric Tuberculous Meningitis. Clin Infect Dis. 2017; 65(8): 1298-307.

PubMed Abstract | Publisher Full Text | Free Full Text

33. Rohlwink UK, Figaji A, Wilkinson KA, et al.: Tuberculous meningitis in children is characterized by compartmentalized immune responses and neural excitotoxicity. Nat Commun. 2019; 10(1): 3767.

PubMed Abstract | Publisher Full Text | Free Full Text

34. Pinon JM, Puygauthier-Toubas $\mathrm{D}$, Lepan $\mathrm{H}$, et al:: Rapid detection of proteins by enzyme-linked immunofiltration assay after transfer onto nitrocellulose membranes. Electrophoresis. 1990; 11(1): 41-5. PubMed Abstract | Publisher Full Text

35. Lin WC, Chen PC, Wang HC, et al.: Diffusion tensor imaging study of white matter damage in chronic meningitis. PLoS One. 2014; 9(6): e98210. PubMed Abstract | Publisher Full Text | Free Full Text

36. Chen $\mathrm{HL}$, $\mathrm{Lu} \mathrm{CH}$, Chang $\mathrm{CD}$, et al.: Structural deficits and cognitive impairment in tuberculous meningitis. BMC Infect Dis. 2015; 15: 279. PubMed Abstract | Publisher Full Text | Free Full Text

37. Tucker EW, Pokkali S, Zhang Z, et al.: Microglia activation in a pediatric rabbit model of tuberculous meningitis. Dis Model Mech. 2016; 9(12): 1497-506. PubMed Abstract | Publisher Full Text | Free Full Text

38. Kim DW, Kim CG, Park SA, et al.: Experience of Dual Time Point Brain F-18 FDG $\mathrm{PET} / \mathrm{CT}$ Imaging in Patients with Infectious Disease. NuCl Med Mol Imaging. 2010; 44(2): 137-42.

PubMed Abstract | Publisher Full Text | Free Full Text

39. Sharma P, Marangmei C: Tubercular Meningitis on 18F-FDG PET/CT: Incidentally Detected and Masquerading as Relapse in a Patient With Ovarian Burkitt Lymphoma. Clin Nucl Med. 2015; 40(7): 606-7. PubMed Abstract | Publisher Full Text

40. Rangan $\mathrm{K}$, Ravina M, Yadav N, et al:: 18F-FDG PET/CT of Tuberculosis Meningitis and Carotid Pseudoaneurysm. Clin Nucl Med. 2017; 42(6): e304-e5. PubMed Abstract | Publisher Full Text

41. Bateman RJ, Xiong C, Benzinger TLS, et al.: Clinical and biomarker changes in dominantly inherited Alzheimer's disease. N Engl J Med. 2012; 367(9): 795-804.

PubMed Abstract | Publisher Full Text | Free Full Text

42. Vlassenko AG, Benzinger TLS, Morris JC: PET amyloid-beta imaging in preclinical Alzheimer's disease. Biochim Biophys Acta. 2012; 1822(3): 370-9. PubMed Abstract | Publisher Full Text | Free Full Tex

43. Thuong NTT, Vinh DN, Hai HT, et al.: Pretreatment Cerebrospinal Fluid Bacterial Load Correlates With Inflammatory Response and Predicts Neurological Events During Tuberculous Meningitis Treatment. J Infect Dis. 2019; 219(6): 986-95.

PubMed Abstract | Publisher Full Text | Free Full Text

44. Heemskerk AD, Donovan J, Thu DDA, et al.: Improving the microbiological diagnosis of tuberculous meningitis: A prospective, international, multicentre comparison of conventional and modified Ziehl-Neelsen stain, GeneXpert, and culture of cerebrospinal fluid. / Infect. 2018; 77(6): 509-15. PubMed Abstract | Publisher Full Text | Free Full Text

45. Marais S, Meintjes G, Pepper DJ, et al.: Frequency, severity, and prediction of tuberculous meningitis immune reconstitution inflammatory syndrome. Clin Infect Dis. 2013; 56(3): 450-60.

PubMed Abstract | Publisher Full Text | Free Full Text
46. Faksri K, Xia E, Ong RT, et al.: Comparative whole-genome sequence analysis of Mycobacterium tuberculosis isolated from tuberculous meningitis and pulmonary tuberculosis patients. Sci Rep. 2018; 8(1): 4910. PubMed Abstract | Publisher Full Text | Free Full Text

47. Ruesen C, Chaidir L, van Laarhoven A, et al.: Large-scale genomic analysis shows association between homoplastic genetic variation in Mycobacterium tuberculosis genes and meningeal or pulmonary tuberculosis. BMC Genomics. 2018; 19(1): 122. PubMed Abstract | Publisher Full Text | Free Full Text

48. Houben RM, Dodd PJ: The Global Burden of Latent Tuberculosis Infection: A Re-estimation Using Mathematical Modelling. PLoS Med. 2016; 13(10): e1002152.

PubMed Abstract | Publisher Full Text | Free Full Text

49. Casadevall A, Pirofski LA: Host-pathogen interactions: redefining the basic concepts of virulence and pathogenicity. Infect Immun. 1999; 67(8): 3703-13. PubMed Abstract | Publisher Full Text | Free Full Text

50. Pirofski LA, Casadevall A: Immune-Mediated Damage Completes the Parabola: Cryptococcus neoformans Pathogenesis Can Reflect the Outcome of a Weak or Strong Immune Response. mBio. 2017; 8(6): e02063-17. PubMed Abstract | Publisher Full Text | Free Full Text

51. Agarwal N, Lamichhane G, Gupta R, et al.: Cyclic AMP intoxication of macrophages by a Mycobacterium tuberculosis adenylate cyclase. Nature. 2009: 460(7251): 98-102.

PubMed Abstract | Publisher Full Text

52. Berg RD, Ramakrishnan L: Insights into tuberculosis from the zebrafish model. Trends Mol Med. 2012; 18(12): 689-90.

PubMed Abstract | Publisher Full Text

53. Kumar P: IFNy-producing CD4 ${ }^{+} \mathbf{T}$ lymphocytes: the double-edged swords in tuberculosis. Clin Trans/ Med. 2017; 6(1): 21.

PubMed Abstract | Publisher Full Text | Free Full Text

54. Xu HB, Jiang RH, Li L, et al.: Diagnostic value of adenosine deaminase in cerebrospinal fluid for tuberculous meningitis: a meta-analysis. Int J Tuberc Lung Dis. 2010; 14(11): 1382-7.

PubMed Abstract

55. Juan RS, Sánchez-Suárezz C, Rebollo MJ, et al.: Interferon gamma quantification in cerebrospinal fluid compared with PCR for the diagnosis of tuberculous meningitis. J Neurol. 2006; 253(10): 1323-30. PubMed Abstract | Publisher Full Text

56. Lu D, Chen C, Yu S, et al.: Diagnosis of Tuberculous Meningitis Using a Combination of Peripheral Blood T-SPOT.TB and Cerebrospinal Fluid Interferon-y Detection Methods. Lab Med. 2016; 47(1): 6-12. PubMed Abstract | Publisher Full Text

57. Yu J, Wang ZJ, Chen LH, et al.: Diagnostic accuracy of interferon-gamma release assays for tuberculous meningitis: a meta-analysis. Int J Tuberc Lung Dis. 2016; 20(4): 494-9.

PubMed Abstract | Publisher Full Text

58. Bahr NC, Halupnick R, Linder G, et al:: Delta-like 1 protein, vitamin D binding protein and fetuin for detection of Mycobacterium tuberculosis meningitis. Biomark Med. 2018; 12(7): 707-16.

PubMed Abstract | Publisher Full Text | Free Full Text

59. Huang TY, Zhang XX, Wu QL, et al.: Antibody detection tests for early diagnosis in tuberculous meningitis. Int J Infect Dis. 2016; 48: 64-9. PubMed Abstract | Publisher Full Text

60. Shah M, Hanrahan C, Wang ZY, et al.: Lateral flow urine lipoarabinomannan assay for detecting active tuberculosis in HIV-positive adults. Cochrane Database Syst Rev. 2016; 2016(5): CD011420.

PubMed Abstract | Publisher Full Text | Free Full Text

61. Gupta RK, Turner CT, Venturini C, et al:: Concise whole blood transcriptional signatures for incipient tuberculosis: a systematic review and patient-level pooled meta-analysis Lancet Respir Med. 2020; 8(4): 395-406.

PubMed Abstract | Publisher Full Text

62. Sweeney TE, Braviak L, Tato CM, et al.: Genome-wide expression for diagnosis of pulmonary tuberculosis: a multicohort analysis. Lancet Infect Dis. 2016 4(3): 213-24.

PubMed Abstract | Publisher Full Text | Free Full Text

63. Marais S, Thwaites G, Schoeman JF, et al: Tuberculous meningitis: a uniform case definition for use in clinical research. Lancet Infectious Dis. 2010; 10(11): 803-12.

PubMed Abstract | Publisher Full Text

64. Solomons R, Grantham M, Marais BJ, et al:: IMCI indicators of childhood TBM at primary health care level in the Western Cape Province of South Africa. Int J TB and Lung Dis. 2016; 20(10): 1309-13.

PubMed Abstract | Publisher Full Text

65. Chegou NN, Walzl G, Bolliger CT, et al.: Evaluation of adapted whole-blood interferon-gamma release assays for the diagnosis of pleural tuberculosis. Respiration. 2008; 76(2): 131-8.

PubMed Abstract | Publisher Full Text

66. Manyelo CM, Solomons RS, Snyders CI, et al: Application of Cerebrospinal Fluid Host Protein Biosignatures in the Diagnosis of Tuberculous Meningitis in Children from a High Burden Setting. Mediators Inflamm. 2019; 2019: 7582948

PubMed Abstract | Publisher Full Text | Free Full Text

67. Manyelo CM, Solomons RS, Snyders CI, et al.: Potential of Host Serum Protein 
Biomarkers in the Diagnosis of Tuberculous Meningitis in Children. Front Pediatr. 2019; 7: 376.

PubMed Abstract | Publisher Full Text | Free Full Text

68. Pormohammad A, Nasiri MJ, McHugh TD, et al.: A Systematic Review and Meta-analysis of the Diagnostic Accuracy of Nucleic Acid Amplification Tests for Tuberculous Meningitis. J Clin Microbiol. 2019; 57(6): e01113-18. PubMed Abstract | Publisher Full Text | Free Full Text

69. Modi M, Sharma K, Sharma M, et al.: Multitargeted loop-mediated isothermal amplification for rapid diagnosis of tuberculous meningitis. In J Tuberc Lung Dis. 2016; 20(5): 625-30.

PubMed Abstract | Publisher Full Text

70. Kohli M, Schiller I, Dendukuri N, et al.: Xpert $^{\circledR}$ MTB/RIF assay for extrapulmonary tuberculosis and rifampicin resistance. Cochrane Database Syst Rev. 2018; 8(8): Cd012768.

PubMed Abstract | Publisher Full Text | Free Full Text

71. Cresswell FV, Bangdiwala AS, Bahr NC, et al.: Can improved diagnostics reduce mortality from Tuberculous meningitis? Findings from a 6.5 -year cohort in Uganda [version 2; peer review: 3 approved]. Wellcome Open Res. 2018; 3: 64.

PubMed Abstract | Publisher Full Text | Free Full Text

72. Sharma K, Sharma M, Chaudhary L, et al.: Comparative evaluation of Xpert MTB/RIF assay with multiplex polymerase chain reaction for the diagnosis of tuberculous meningitis. Tuberculosis (Edinb). 2018; 113: 38-42. PubMed Abstract | Publisher Full Text

73. Patel VB, Connolly C, Singh R, et al.: Comparison of amplicor and GeneXpert MTB/RIF tests for diagnosis of tuberculous meningitis. J Clin Microbiol. 2014 52(10): 3777-80.

PubMed Abstract | Publisher Full Text | Free Full Text

74. Chakravorty S, Simmons AM, Rowneki M, et al.: The New Xpert MTB/RIF Ultra: Improving Detection of Mycobacterium tuberculosis and Resistance to Rifampin in an Assay Suitable for Point-of-Care Testing. mBio. 2017; 8(4). PubMed Abstract | Publisher Full Text | Free Full Text

75. Bahr NC, Nuwagira E, Evans EE, et al.: Diagnostic accuracy of Xpert MTB/RIF Ultra for tuberculous meningitis in HIV-infected adults: a prospective cohort study. Lancet Infect Dis. 2018; 18(1): 68-75.

PubMed Abstract | Publisher Full Text | Free Full Text

76. Cresswell F, Tugume L, Bahr NC, et al.: Xpert MTB/Rif Ultra for the Diagnosis of HIV-Associated Tuberculous Meningitis: A Prospective Validation. 2019. Reference Source

77. Group WHOTE: Non-inferiority analysis of Xpert MTB/RIF Ultra compared to Xpert MTB/RIF. Geneva: World Health Organisation. 2017.

78. Cresswell FV, Tugume L, Bahr NC, et al.: Xpert MTB/RIF Ultra for the diagnosis of HIV-associated tuberculous meningitis: a prospective validation study. Lancet Infect Dis. 2020; 20(3): 308-317.

PubMed Abstract | Publisher Full Text | Free Full Tex

79. Donovan J, Thu DDA, Phu NH, et al.: Xpert MTB/RIF Ultra versus Xpert MTB/RIF for the diagnosis of tuberculous meningitis: a prospective randomised, diagnostic accuracy study. Lancet Infect Dis. 2020; 20(3): 299-307.

PubMed Abstract | Publisher Full Text | Free Full Text

80. Gupta R, Thakur R, Gupta P, et al.: Evaluation of Geno Type MTBDRplus Line Probe Assay for Early Detection of Drug Resistance in Tuberculous Meningitis Patients in India. J Glob Infect Dis. 2015; 7(1): 5-10. PubMed Abstract | Publisher Full Text | Free Full Text

81. Zong K, Luo C, Zhou H, et al:: Xpert MTB/RIF assay for the diagnosis of rifampicin resistance in different regions: a meta-analysis. BMC Microbiol. 2019; 19(1): 177

PubMed Abstract | Publisher Full Text | Free Full Text

82. Nhu NT, Heemskerk D, Thu do DA, et al.: Evaluation of GeneXpert MTB/RIF for diagnosis of tuberculous meningitis. J Clin Microbiol. 2014; 52(1): 226-33. PubMed Abstract | Publisher Full Text | Free Full Text

83. Patel VB, Theron G, Lenders $L$, et al.: Diagnostic accuracy of quantitative PCR (Xpert MTB/RIF) for tuberculous meningitis in a high burden setting: a prospective study. PLoS Med. 2013; 10(10): e1001536. PubMed Abstract | Publisher Full Text | Free Full Tex

84. Bahr NC, Marais S, Caws M, et al.: GeneXpert MTB/Rif to Diagnose Tuberculous Meningitis: Perhaps the First Test but not the Last. Clin Infect Dis. 2016; 62(9): 1133-5.

PubMed Abstract | Publisher Full Text | Free Full Text

85. Boyles T: Xpert Ultra's place in the diagnosis of tuberculous meningitis.

lancet Infect Dis. 2018: 18(3): 248-9.

PubMed Abstract | Publisher Full Text
86. Ai JW, Zhou X, Xu T, et al.: CRISPR-based rapid and ultra-sensitive diagnostic test for Mycobacterium tuberculosis. Emerg Microbes Infect. 2019; 8(1): 1361-9.

PubMed Abstract | Publisher Full Text

87. Wilson MR, Sample HA, Zorn KC, et al.: Clinical Metagenomic Sequencing for Diagnosis of Meningitis and Encephalitis. N EnglJ Med. 2019; 380(24): 2327-40.

PubMed Abstract | Publisher Full Text | Free Full Text

88. Wang S, Chen Y, Wang D, et al.: The Feasibility of Metagenomic Next-Generation Sequencing to Identify Pathogens Causing Tuberculous Meningitis in Cerebrospinal Fluid. Front Microbiol. 2019; 10: 1993.

PubMed Abstract | Publisher Full Text | Free Full Text

89. Quan J, Langelier C, Kuchta A, et al.: FLASH: a next-generation CRISPR diagnostic for multiplexed detection of antimicrobial resistance sequences. Nucleic Acids Res. 2019; 47(14): e83.

PubMed Abstract | Publisher Full Text | Free Full Text

90. Coll F, McNerney R, Preston MD, et al.: Rapid determination of anti-tuberculosis drug resistance from whole-genome sequences. Genome Med. 2015; 7(1): 51 . PubMed Abstract | Publisher Full Text | Free Full Text

91. Ramachandran $P$, Cresswell F, Langelier $C$, et al.: Illuminating Tuberculosis Meningitis with Metagenomics and FLASH Enrichment. Neurology. 2019; S45: 005.

Reference Source

92. Bahr NC, Tugume L, Boulware DR: A Word of Caution in Considering the Use of the Lipoarabinomannan Lateral Flow Assay on Cerebrospinal Fluid for Detection of Tuberculous Meningitis. J Clin Microbiol. 2016; 54(1): 241-2. PubMed Abstract | Publisher Full Text | Free Full Text

93. Kwizera R, Cresswell FV, Mugumya G, et al.: Performance of Lipoarabinomannan Assay using Cerebrospinal fluid for the diagnosis of Tuberculous meningitis among HIV patients [version 2; peer review: 2 approved]. Wellcome Open Res. 2019; 4: 123. PubMed Abstract | Publisher Full Text | Free Full Text

94. Cox JA, Lukande RL, Kalungi S, et al.: Accuracy of Lipoarabinomannan and Xpert MTB/RIF Testing in Cerebrospinal Fluid To Diagnose Tuberculous Meningitis in an Autopsy Cohort of HIV-Infected Adults. J Clin Microbiol. 2015; 53(8): 2667-73.

PubMed Abstract | Publisher Full Text | Free Full Text

95. Siddiqi OK, Birbeck GL, Ghebremichael M, et al.: Prospective Cohort Study on Performance of Cerebrospinal Fluid (CSF) Xpert MTB/RIF, CSF Lipoarabinomannan (LAM) Lateral Flow Assay (LFA), and Urine LAM LFA for Diagnosis of Tuberculous Meningitis in Zambia. / Clin Microbiol. 2019; 57(8): pii: e00652-19.

PubMed Abstract | Publisher Full Text | Free Full Text

96. Broger $T$, Sossen $B$, du Toit $E$, et al.: Novel lipoarabinomannan point-of-care tuberculosis test for people with HIV: a diagnostic accuracy study, Lancet Infect Dis. 2019; 19(8): 852-61.

PubMed Abstract | Publisher Full Text | Free Full Text

97. Quinn CM, Kagimu E, Okirwoth M, et al:: Fujifilm SILVAMP TB LAM assay on cerebrospinal fluid for the detection of tuberculous meningitis in HIV-infected adults. Clin Infect Dis. 2021; ciaa1910. PubMed Abstract | Publisher Full Text

98. Boyles T, Stadelman A, Ellis JP, et al.: The diagnosis of tuberculous meningitis in adults and adolescents: protocol for a systematic review and individual patient data meta-analysis to inform a multivariable prediction model [version 2; peer review: 1 approved, 1 approved with reservations]. Wellcome Open Res. 2019; 4: 19. Publisher Full Text

99. Cohen J, Vincent JL, Adhikari NK, et al.: Sepsis: a roadmap for future research. Lancet Infect Dis. 2015; 15(5): 581-614. PubMed Abstract | Publisher Full Tex

100. Imperial MZ, Nahid P, Phillips PPJ, et al.: A patient-level pooled analysis of treatment-shortening regimens for drug-susceptible pulmonary tuberculosis. Nat Med. 2018; 24(11): 1708-15. PubMed Abstract | Publisher Full Text | Free Full Text

101. Misra UK, Kalita J, Nair PP: Role of aspirin in tuberculous meningitis: a randomized open label placebo controlled trial. J Neurol Sci. 2010; 293(1-2): $12-7$

PubMed Abstract | Publisher Full Text

102. Coulter JB, Baretto RL, Mallucci $C L$, et al:: Tuberculous meningitis: protracted course and clinical response to interferon-gamma. Lancet Infect Dis. 2007; 7(3): $225-32$ PubMed Abstract | Publisher Full Tex 


\section{Open Peer Review}

\section{Current Peer Review Status:}

\section{Version 3}

Reviewer Report 04 February 2021

https://doi.org/10.21956/wellcomeopenres.18255.r42363

(C) 2021 Zunt J. This is an open access peer review report distributed under the terms of the Creative Commons Attribution License, which permits unrestricted use, distribution, and reproduction in any medium, provided the original work is properly cited.
Joseph Zunt
Department of Neurology, Harborview Medical Center, University of Washington, Seattle, WA, USA
No additional comments.
Competing Interests: No competing interests were disclosed.
Reviewer Expertise: Neurology, infectious diseases, epidemiology, global health
I confirm that I have read this submission and believe that I have an appropriate level of expertise to confirm that it is of an acceptable scientific standard.

\section{Version 2}

Reviewer Report 15 December 2020

\section{https://doi.org/10.21956/wellcomeopenres.17659.r41505}

(c) 2020 Griffiths $M$. This is an open access peer review report distributed under the terms of the Creative Commons Attribution License, which permits unrestricted use, distribution, and reproduction in any medium, provided the original work is properly cited.

\section{Michael J. Griffiths}

Institute of Infection and Global Health, University of Liverpool, Liverpool, UK

Overall the manuscript represents an excellent review of recent developments in tuberculous meningitis pathogenesis and diagnostics. I agree with changes following the first reviewer's, $\mathrm{Dr}$ Scriven, suggestions. I add two relatively modest comments on the document. 
Utilising host biomarkers for TBM diagnostics are an exciting development. In the section on 'Biomarkers in Children', the authors describe the results of two studies (by the same group) using different combinations of host CSF biomarkers among children $[15,64]$. The authors should state what type of host markers (i.e. a mixture of cytokine and soluble mediators) were measured in the studies (using ELISA and Luminex platform). In the follow-up study [64], a relatively small number of patients $(n=47)$ were tested in un-blinded study design. The STARD diagram shows a series of markers ( $n=69)$ were measured before the samples were then split into two clinical groups (TBM [definite/probable] $n=23$ or non-TBM $n=24$ ) and later the accuracy of the best combination of markers reported. Given the small size and unblinded design, the results of these studies (particularly the latter) could be summarized further and technical study limitations stated (beyond using CSF).

In the section on TBM diagnostics- many different types of host biomarkers are now being measured and their diagnostic potential beginning to be assessed in TB, including host transcripts. There are a few publications reporting on host transcripts among TBM patients, including work by the authors (Rohlwink UK et al. 20191; Hemingway C et al. 20172). While diagnostic accuracy of RNA signatures in TBM have not been assessed in these studies (as stated in Figure 4), there is in an enlarging body of work in pulmonary TB. Reference to some of the larger host transcript studies assessing diagnostic accuracy may be worth mentioning, as these studies highlight the potential strengths/challenges ahead for this approach in TBM (Gupta RK et al. 20203; Sweeney TE et al. $2016^{4}$.

\section{References}

1. Rohlwink U, Figaji A, Wilkinson $\mathrm{K}$, Horswell S, et al.: Tuberculous meningitis in children is characterized by compartmentalized immune responses and neural excitotoxicity. Nature Communications. 2019; 10 (1). Publisher Full Text

2. Hemingway $C$, Berk M, Anderson ST, Wright VJ, et al.: Childhood tuberculosis is associated with decreased abundance of T cell gene transcripts and impaired T cell function.PLoS One. 2017; 12 (11): e0185973 PubMed Abstract | Publisher Full Text

3. Gupta R, Turner C, Venturini C, Esmail H, et al.: Concise whole blood transcriptional signatures for incipient tuberculosis: a systematic review and patient-level pooled meta-analysis. The Lancet Respiratory Medicine. 2020; 8 (4): 395-406 Publisher Full Text

4. Sweeney T, Braviak L, Tato C, Khatri P: Genome-wide expression for diagnosis of pulmonary tuberculosis: a multicohort analysis. The Lancet Respiratory Medicine. 2016; 4 (3): 213-224 Publisher Full Text

Is the topic of the review discussed comprehensively in the context of the current literature?

Yes

Are all factual statements correct and adequately supported by citations?

Yes

Is the review written in accessible language?

Yes

Are the conclusions drawn appropriate in the context of the current research literature? 
Yes

Competing Interests: No competing interests were disclosed.

Reviewer Expertise: Paediatric neurology, CNS infections, diagnostics.

I confirm that I have read this submission and believe that I have an appropriate level of expertise to confirm that it is of an acceptable scientific standard.

Author Response 12 Jan 2021

Fiona Cresswell, London School of Hygiene and Tropical Medicine, London, UK

We would like to thank Dr Griffiths for this expert review.

In response to comment 1.

Thank you for raising the point requiring further information including the type of host biomarkers and assay methods, and study limitations. For the study (reference 15), we have added the following text: 'In a study evaluating disease-specific CSF biomarkers of paediatric TBM, a combination of 28 cytokines and soluble mediators were assessed; 27 host biomarkers by Luminex multiplex bead array technology (Bio-Rad Laboratories) and cathelicidin LL-37 concentration by using an enzyme-linked immunosorbent assay (ELISA) kit (USCN Life Science).'

For the follow-up study (reference 64), we have added the following text: 'In this study investigating 69 potentially-useful host biomarkers for childhood TBM ( 23 children with TBM and 24 controls) comprising a combination of cytokines and soluble mediators in CSF (cathelicidin LL-37 by using an ELISA kit purchased from Elabscience Biotechnology Inc. (catalog \#E-EL-H2438) and the rest by Luminex assay).

Study limitations were addressed by adding the following text: 'Limitations of the studies assessing CSF host biomarkers in childhood TBM include relatively small sample size, and therefore few children with confirmed TBM, confirmed meningitis due to other pathogens, and confirmed HIV co-infection. External validation is a necessity in order to generalize the clinical usefulness of the prediction model in an independent group of patients. Despite the potential of CSF-based biosignatures, a further limitation is the invasive nature of CSF collection, and blood or urine-based inflammatory biosignatures require exploration.'

\section{Comment 2.}

Thank you for raising the point relating to the utility of RNA transcripts as a biomarker for TBM diagnosis. Indeed, a number of recent studies in adults and children have utilised the host transcriptome to better understand the pathogenesis of TBM. Work is underway to use the host transcriptome and develop a machine learning classifier to aid the diagnosis of TBM but this work is unpublished.

We have added the following text to the paper: "In the field of pulmonary tuberculosis, host RNA transcriptomic signatures have been leveraged to predict incipient and active tuberculosis with moderate short-term (<3 month) sensitivity (41-81\%) [Gupta, Lancet Resp Med, 2020]. A whole blood 3-gene signature (GBP5, DUSP3, KLF2) has been shown to 
accurately differentiate active pulmonary tuberculosis from healthy controls (area under receiver operator curve, AUC 0.90), latent TB infection (AUC 0.88) and other diseases (AUC 0.84) [Sweeney, Lancet Resp Med, 2016]. Whether this 3-gene signature in whole blood has diagnostic value in TBM, whereby the inflammation can be compartmentalised to the CNS, remains to be investigated. An ongoing study in Uganda is adopting a machine learning approach to develop a classifier that categorises patients as TBM or not-TBM based on their CSF RNA signature. The classifier. Four genes predominantly predicted TBM (FTL, NFKBIA, SOD2, GBP5) and the classifier has good sensitivity and specificity (unpublished data)."

Many thanks again for taking the time to improve the manuscript through these comments.

Competing Interests: No competing interests were disclosed.

Reviewer Report 14 December 2020

https://doi.org/10.21956/wellcomeopenres.17659.r41544

(C) 2020 Zunt J. This is an open access peer review report distributed under the terms of the Creative Commons Attribution License, which permits unrestricted use, distribution, and reproduction in any medium, provided the original work is properly cited.

\section{Joseph Zunt}

Department of Neurology, Harborview Medical Center, University of Washington, Seattle, WA, USA

This is a thorough review of current developments in the field of tuberculous meningitis. They included a very nice inclusion of promising new technology, such as CRISPR-MTB and metagenomics. Although not an obligatory recommended change, given the multiple diagnostic assays discussed, I think the reader would find useful a table that listed the various assays with their accompanying sensitivities, specificities and limitations.

\section{Minor recommended edits:}

I agree with Reviewer 1 that the "Rich Focus" was not "refuted" and the editorial change to "potentially challenges" is perhaps not warranted, as there may be more than one pathway to development of meningitis - an event simultaneous with initial infection and a moredelayed event, such as that proposed by Rich and McCordock.

On page 9, under Pathogen-based diagnostics, the authors start discussing the "potential to score points" without reference to any specific diagnostic criteria - please edit accordingly.

Page 10; the authors discuss a study in Uganda - It would be helpful to know if the "reference of definite/probable TBM" was made by culture, biopsy or other. Later on this same page, they reference a study of CRISPR-MTB and Xpert that used a standard of "clinical TB" - It would be useful to know what this clinical diagnosis was based on - clinical + CSF findings + neuroimaging findings? 
There were multiple minor grammatical errors that should be corrected:

P 3. Second to last sentence in the Introduction - "that" should be removed.

P 5. Second paragraph - "cytokine" should be "cytokines".

P6. First paragraph - please remove redundant sentence.

First sentence under Neuroimaging in pathogenesis studies - "has" should be "have".

As mentioned by reviewer 1, comma should follow "anterior cingulate gyrus".

P8. Third paragraph - "where" should be "were".

P9. Third paragraph - "tests" should be "test".

P10. Sixth paragraph - "stanrdards" should be "standards".

P11. Second paragraph - "is susceptibility" should be "its susceptibility".

Is the topic of the review discussed comprehensively in the context of the current literature?

Yes

Are all factual statements correct and adequately supported by citations? Yes

Is the review written in accessible language?

Yes

Are the conclusions drawn appropriate in the context of the current research literature? Yes

Competing Interests: No competing interests were disclosed.

Reviewer Expertise: Neurology, infectious diseases, epidemiology, global health

I confirm that I have read this submission and believe that I have an appropriate level of expertise to confirm that it is of an acceptable scientific standard.

Author Response 12 Jan 2021

Fiona Cresswell, London School of Hygiene and Tropical Medicine, London, UK

We sincerely thank Dr Zunt for his expert review and suggestions.

In response to major comment:

We have added a table summarising the characteristics of CSF tests for TBM and added a 
couple of lines about CSF FujiLAM following a recent publication relating to this assay in TBM.

In response to minor comments:

1. We have edited the text to reflect the fact that there may be more than one route to TBM disease.

2. We have removed this text about the points relating to the reference standard in the interest of brevity.

3. In the Ugandan study MGIT culture and Xpert were used alongside Ultra, this detail has been added to the paper. In the CRISPR study "clinical TB" was as determined by the physician based on clinical presentation imaging and response to TB therapy. This has been added to the paper.

We have rectified the multiple typos spotted.

Many thanks for your suggestions which have improved the manuscript.

Competing Interests: No competing interests were disclosed.

Reviewer Report 02 September 2020

https://doi.org/10.21956/wellcomeopenres.17659.r39409

(c) 2020 Scriven J. This is an open access peer review report distributed under the terms of the Creative Commons Attribution License, which permits unrestricted use, distribution, and reproduction in any medium, provided the original work is properly cited.

James E. Scriven

University of Birmingham, Birmingham, UK

Thank you for taking on board my comments and making the changes and clarifications detailed in your response. I am happy that the sections previously highlighted have now been explained fully.

The only think I have noticed on the re-reading is the second sentence in the Brain Injury Markers section (copied in below) doesn't quite make sense.Could the authors please review this. I think there may be some punctuation (and possibly words) missing?

".....In lumbar CSF of children with TBM, S100B and NSE (structural proteins of the CNS, and biomarkers of CNS tissue damage) at disease onset were associated with poor outcome, as was highest concentration overall and an increasing profile over time in S100B, NSE, and GFAP neuromarker concentrations increased over time in those who died (whilst inflammatory markers decreased), and were overall highest in those with cerebral infarction ${ }^{32}$."

Is the topic of the review discussed comprehensively in the context of the current 


\author{
literature? \\ Yes \\ Are all factual statements correct and adequately supported by citations? \\ Yes \\ Is the review written in accessible language? \\ Yes \\ Are the conclusions drawn appropriate in the context of the current research literature? \\ Yes \\ Competing Interests: No competing interests were disclosed. \\ Reviewer Expertise: Infectious Diseases; CNS infections; immunology \\ I confirm that I have read this submission and believe that I have an appropriate level of \\ expertise to confirm that it is of an acceptable scientific standard.
}

\title{
Version 1
}

Reviewer Report 13 January 2020

https://doi.org/10.21956/wellcomeopenres.16971.r36984

(c) 2020 Scriven J. This is an open access peer review report distributed under the terms of the Creative Commons Attribution License, which permits unrestricted use, distribution, and reproduction in any medium, provided the original work is properly cited.

\section{James E. Scriven}

University of Birmingham, Birmingham, UK

Thank you for asking me to review this manuscript.

\section{General comments}

This is a comprehensive review of TB meningitis pathogenesis and diagnostics with the stated aim of concentrating on the most recent developments (last 5 years).

The authors should be commended on providing a detailed review. They have included the vast majority of recently published studies but should also include the Vietnamese study published in Lancet ID this month by Donovan et al that compares Xpert against XpertUltra in TBM (and compare it to their recently published study in HIV-TBM patients). ${ }^{1}$

My main criticism of the review relates to the section on TBM pathogenesis which requires further work to improve understanding for the reader. There are several sections where the 
authors have listed a series of findings from separate immunological studies but do not introduce the concept fully to the reader and do not draw the findings together at the end of each section to provide an overall interpretation or explanation for the reader. Some further explanation around these concepts would significantly improve the review.

This is particularly true for the section covering host genetic factors and the influence of LTA4H genotype on host response and outcome. This is a really important and fascinating piece of science but for readers not already familiar with this concept this section is confusing. The authors should provide further explanation, particularly regarding the differing inflammatory states associated with the three genotypes, and why it is important. They should consider including discussion and reference of the original paper by Tobin et al (Cell 2012). ${ }^{2}$

\section{Specific comments:}

\section{Introduction}

The GeneXpert test performances should be referenced. I think there is a typo on line 7 ("traditional" should be "traditionally")?

\section{TBM pathogenesis - Dissemination to the CNS}

The use of the word refute with regard to the Rich focus theory of TBM pathogenesis could be regarded as a bit strong. Do the authors think that the references provided fully support this statement?

\section{TBM pathogenesis - Host immune response to TB infection in the CNS}

The first two sentences of the first paragraph in this section should probably contain a reference.

In the second paragraph, the association between death and lower CSF leukocyte count should include the $p=$ value.

Further explanation/interpretation of the lipid mediator findings and flow cytometery findings would help improve understanding of this section.

The authors should also consider discussing the Vietnamese phase II trial of Aspirin by Mai et al (Ref 94), further in this section. They very briefly mention it in the Discussion section but a more detailed discussion is probably warranted and it may be appropriate to do so here.

\section{TBM pathogenesis - Host genetic and metabolic factors.}

As mentioned above, for readers not familiar with the original studies this section discussing LTA4H genotypes is difficult to understand as it is currently written. It would benefit from re-wording and further explanation, particularly a sentence or two to introduce the concept at the beginning of the paragraph and a precise explanation of the effects of LTA4H genotype on inflammation, steroid responsiveness and outcome (with reference to the original paper, Tobin et al. Cell. 2012). ${ }^{2}$

The authors should also consider adding a couple sentences to the section on tryptophan to provide some additional information about this study and providing a more comprehensive 
explanation for the association between low levels and better survival.

\section{Figure 2.}

The figure should make it clear that the patients in $A$ and $B$ have all received steroids. It would also aid understanding if the figure legend also contained the $p=v a l u e s$ with respect to the differing outcomes quoted for graph A and B. The final sentence looks like it might contain a typo:

"In a recessive model, TT genotype versus CT/TT combined had HR 0.81 (95\% CI 0.41-1.62, $p=$ .550) in severe and 0.31 (95\% CI 0.04-2.25, $p=.156)$ in milder disease."

I think the comparison stated in the model should be be TT vs CT/CC?

\section{TBM pathogenesis - HIV co-infection and IRIS}

In the first paragraph (line 9, copied below), a comparison in neutrophil counts and mortality is presented between patients with a CD4 count $>150$, CD4 $<150$ and HIV negative.

"PLWHIV with CD4+ T-cell counts $<150$ cells/ $\mu L$ showed higher median CSF neutrophil percentage (25\%), cytokine concentrations and 9-month mortality (44\%) than those with a CD4+ T-cell count $\geq 150$ cells/ $\mu \mathrm{L}$ (neutrophils $10 \% ; \boldsymbol{P}=. \mathbf{0 2 1}$, mortality 13\%) and patients without HIV infection (neutrophils 5\%; $\boldsymbol{P}<.0001$, mortality 18\%). These findings, amongst others, suggest a role for neutrophils in the immunopathogenesis of HIV-associated TBM."

However, there are only two $p$ values included and it is not clear whether they refer to neutrophils or mortality. Could the authors please alter this to make it a little clearer (and if appropriate add the two additional p-values).

\section{TBM pathogenesis - Pathogenesis of TBM in childhood}

I don't think this section in its current form particularly adds to the review and there is no new data. I would suggest this section is either expanded (to further discuss the differences between adult and paediatric patients with TBM and the pathological processes underlying these differences) or dropped. If the authors do decide to drop it they could consider amalgamating the statements about Donald and Schoeman's TBM and milary TB findings into the earlier section: "Dissemination to the central nervous system".

\section{TBM pathogenesis - Brain injury markers}

This paragraph would also benefit from further explanation so that the reader can appreciate the importance of the findings. Further detail about the brain injury markers S100B and NSE would be helpful (particularly whether they are used in other neurological conditions). Further text is also required to explain what the CSF transcriptomic signature means.

\section{TBM pathogenesis - Neuroimaging in pathogenesis studies}

Is there a comma missing here?: "anterior cingulate gyrus parahippocampal gyrus and globus pallidus".

The novel imaging studies reporting structural damage in cortical and subcortical areas are interesting. Perhaps the authors could expand slightly to suggest the potential implications 
of this?

TBM pathogenesis - Host pathogen interactions.

This section discusses the damage response framework concept and applies it to TBM. I am not sure why the first sentence includes data on global latent TB prevalence - it doesn't seem directly relevant to this section.

It may improve the review if the authors expanded this section slightly and used it as a summary to draw together all the immunological findings discussed above. Particularly to draw attention to the importance of neutrophils.

\section{TBM diagnostics}

This section provides a good summary of host-based and pathogen-based diagnostics and reads well.

With regard to the host-based biomarkers, some of the pooled sensitivities appear promising but have drawbacks. It would be useful if the authors could provide a concluding comment at the end of the section discussing whether there is any future in these modalities (e.g. are any of those mentioned being taken forward into further trials? Are there any plans to introduce any of these tests?).

Regarding the performance of XpertUltra in TBM. The authors have mentioned their prospective study examining its performance in Uganda (reference 70). They should emphasize that these results were in patients with HIV infection. They should also mention the similar study from Vietnam published alongside theirs this month in Lancet ID by Donovan et al which reports lower sensitivities and no significant improvement on Xpert. They should discuss why this might be.

\section{References}

1. Donovan J, Thu D, Phu N, Dung V, et al.: Xpert MTB/RIF Ultra versus Xpert MTB/RIF for the diagnosis of tuberculous meningitis: a prospective, randomised, diagnostic accuracy study. The Lancet Infectious Diseases. 2020. Publisher Full Text

2. Tobin DM, Roca FJ, Oh SF, McFarland R, et al.: Host genotype-specific therapies can optimize the inflammatory response to mycobacterial infections.Cell. 2012; 148 (3): 434-46 PubMed Abstract | Publisher Full Text

Is the topic of the review discussed comprehensively in the context of the current literature?

Yes

Are all factual statements correct and adequately supported by citations? Yes

Is the review written in accessible language?

Yes

Are the conclusions drawn appropriate in the context of the current research literature? 
Yes

Competing Interests: No competing interests were disclosed.

Reviewer Expertise: Infectious Diseases; CNS infections; immunology

I confirm that I have read this submission and believe that I have an appropriate level of expertise to confirm that it is of an acceptable scientific standard, however I have significant reservations, as outlined above.

Author Response 21 Jun 2020

Fiona Cresswell, London School of Hygiene and Tropical Medicine, London, UK

We thank the reviewer for taking the time to provide this very considered and detailed review. We have taken Dr Scriven's comments on board, modified the paper accordingly, and we hope the article has been strengthened as a result. In response to Dr Scriven's comments we have made the following changes:

Added a paragraph relating to the two recent studies on Xpert MTB/RifUltra as suggested.

We have added a reference to the introduction line 7 as suggested

The statement regarding 'refuting' the Rich focus has been made less conclusive

$P$ value added to the paragraph about CSF leucocytes

Further developed the sections relating to pathogenesis:

expanded section on aspirin study and lipid mediators

expanded background on LTA4H

expanded evidence around brain injury markers

We have not added further information on tryptophan in the interest of word limit as there is already a full paragraph on this topic

The section on pathogenesis of TBM in childhood has been removed as suggested. Donald and Schoeman's TBM and miliary TB findings are now included in the "Dissemination to the central nervous system" section

We have added a summary statement on TBM biomarkers explaining that despite extensive research on this topic there are no currently biomarkers with adequate performance to be commercially viable in TBM diagnostics.

Typos and grammatical errors have been corrected. Many thanks!

We are very grateful for Dr Scriven's expertise and hope he is satisfied with the updated article.

Competing Interests: No competing interests were disclosed. 